\title{
SOEP
}

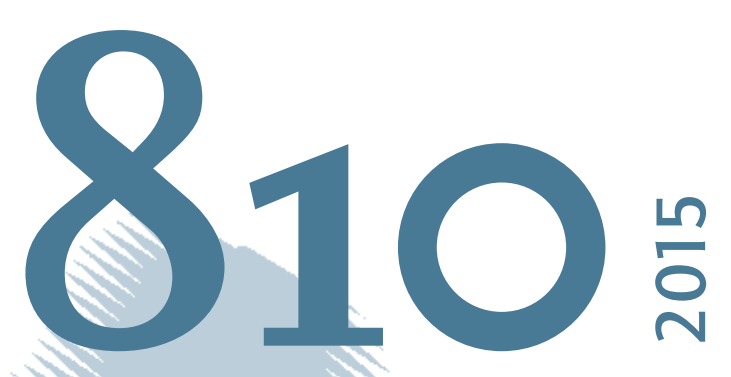

SOEPpapers

on Multidisciplinary Panel Data Research

\section{How a universal music education program affects time use, behavior, and school attitude}


This series presents research findings based either directly on data from the German SocioEconomic Panel study (SOEP) or using SOEP data as part of an internationally comparable data set (e.g. CNEF, ECHP, LIS, LWS, CHER/PACO). SOEP is a truly multidisciplinary household panel study covering a wide range of social and behavioral sciences: economics, sociology, psychology, survey methodology, econometrics and applied statistics, educational science, political science, public health, behavioral genetics, demography, geography, and sport science.

The decision to publish a submission in SOEPpapers is made by a board of editors chosen by the DIW Berlin to represent the wide range of disciplines covered by SOEP. There is no external referee process and papers are either accepted or rejected without revision. Papers appear in this series as works in progress and may also appear elsewhere. They often represent preliminary studies and are circulated to encourage discussion. Citation of such a paper should account for its provisional character. A revised version may be requested from the author directly.

Any opinions expressed in this series are those of the author(s) and not those of DIW Berlin. Research disseminated by DIW Berlin may include views on public policy issues, but the institute itself takes no institutional policy positions.

The SOEPpapers are available at

http://www.diw.de/soeppapers

\section{Editors:}

Jan Goebel (Spatial Economics)

Martin Kroh (Political Science, Survey Methodology)

Carsten Schröder (Public Economics)

Jürgen Schupp (Sociology)

Conchita D'Ambrosio (Public Economics)

Denis Gerstorf (Psychology, DIW Research Director)

Elke Holst (Gender Studies, DIW Research Director)

Frauke Kreuter (Survey Methodology, DIW Research Fellow)

Frieder R. Lang (Psychology, DIW Research Fellow)

Jörg-Peter Schräpler (Survey Methodology, DIW Research Fellow)

Thomas Siedler (Empirical Economics)

C. Katharina Spieß (Education and Family Economics)

Gert G. Wagner (Social Sciences)

ISSN: 1864-6689 (online)

German Socio-Economic Panel (SOEP)

DIW Berlin

Mohrenstrasse 58

10117 Berlin, Germany

Contact: Uta Rahmann | soeppapers@diw.de

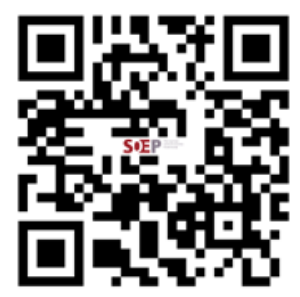




\title{
How a universal music education program affects time use, behavior, and school attitude
}

\author{
Adrian Hille $\mathrm{a}^{\mathrm{a} b}$ \\ ${ }^{a}$ German Institute for Economic Research (DIW Berlin), Research Infrastructure Socio-Economic Panel Study, \\ Mohrenstr. 58, 10117 Berlin, Germany \\ ${ }^{b}$ DIW Berlin Graduate Center, Free University Berlin
}

\begin{abstract}
It is still widely debated how non-cognitive skills can be affected by policy intervention. For example, universal music education programs are becoming increasingly popular among policy makers in Germany and other developed countries. These are intended to give children from poor families the opportunity to learn a musical instrument. Moreover, policymakers present these programs as innovative policies that are important for the personality development of young children. However, the effects of universal music education on such outcomes are not yet sufficiently studied. This paper analyses the Jedem Kind ein Instrument (an instrument for every child) program in the German state of North Rhine-Westphalia. To do so, data from the German household panel studies SOEP and FiD are combined with regional data on primary and music schools. Using a difference-in-differences estimator, I show that the program successfully increases music participation among disadvantaged children. It does so more effectively than the alternative policy of reducing fees at public music schools. I further find that participation reduces conduct problems and improves student teacher relationships, especially among boys.
\end{abstract}

JEL classification: I21, J24, Z18

Keywords: Music, non-cognitive skills, inequality, SOEP, policy evaluation, non-formal education

Email address: ahille@diw.de (Adrian Hille) 


\section{Introduction}

The importance of personality traits and other non-cognitive skills for educational and labor market success is widely acknowledged (e.g. Almlund et al., 2011; Heckman and Kautz, 2012; Heineck and Anger, 2010). Non-cognitive skills are particularly malleable during childhood (Heckman and Kautz, 2014), although it is still widely debated how they can be successfully affected by policy interventions. Model programs are regularly found to be more successful than large-scale policies, partly due to the fact that they are typically more carefully implemented and evaluated (Currie, 2001). For example, the Perry Preschool Program has longlasting positive effects on non-cognitive skills (Heckman et al., 2013), in contrast to Head Start, a publicly funded program that covers all of the United States of America (e.g. Barnett, 2011).

As one possible intervention for non-cognitive skill development, universal music education programs are increasingly popular among policymakers around the world. Most existing programs are inspired by the famous Venezuelian youth orchestras, known as El Sistema, which were established in 1975 by José Antonio Abreu (Creech et al., 2013). These programs, organized by local communities or schools, aim to provide deprived children access to music education. In addition to the regular school curriculum, participating children learn to play a musical instrument for several years. Lessons are taught in small groups or orchestras, with a duration between one or two hours per week in developed countries (Hille, 2010; JeKi-Stiftung, 2014) to several hours per day in the original El Sistema program (Creech et al., 2013).

In Germany, the country in the focus for this study, the most prominent example is the Jedem Kind ein Instrument program (an instrument for every child, henceforth abbreviated as JeKi). Created in 2007 as a pilot project, JeKi reaches, as of 2015, almost all primary schools in 3 of Germany's 16 federal states: North Rhine-Westphalia, Hamburg, and Saxony. With an annual subsidy of 10 million Euros from North Rhine-Westphalia's federal state government, for instance, and further amounts from other administrations, the program receives substantial public funding (JeKi-Stiftung, 2014).

While cultural partaking is formally stated as the primary objective for JeKi and similar programs, policymakers praise the benefits of universal music education for personality development (e.g. BSB, 2009). El Sistema aims at nothing less than "to affect social change through the provision of musical ... opportunities for young people from poor and vulnerable communities" (Creech et al., 2013, p. 17). In their 2013 coalition agreement, the German federal government's ruling parties (CDU, CSU and SPD) stated that, "cultural education is essential for the personality development of young people, as well as their social skills" (CDU, 2013, p. 90). If universal music education has the potential to foster non-cognitive skills, the increasing political willingness to invest in such policies might be an innovative approach to improve educational opportunities, especially for children from disadvantaged social backgrounds.

However, political hopes related to the wide range of benefits that universal music education is believed to have stand in stark contrast to a lack of empirical research on this topic. While (voluntary) extracurricular music training is found beneficial for cognitive skills and is likely to also improve non-cognitive skills (Hille and Schupp, 2015; Schellenberg, 2004; Winner et al., 2013), few researchers study the effects of universal music education policies on non-music related outcomes. In an extensive meta-study of 85 research papers evaluating 44 programs in 
19 countries, Creech et al. (2013) find mostly qualitative evidence, according to which program participants had higher self-esteem, better listening skills, better social skills, a more pro-social behavior, higher academic aspirations, and better academic achievement. However, most of these effects were found for small and selective samples. Almost all studies were of low academic quality or carried out by program administrators themselves. To my knowledge, not one sufficiently takes endogenous selection into account (Creech et al., 2013).

For the German JeKi program, Roden et al. (2014) find that program participants improved their working memory in comparison to students receiving an intensified natural science curriculum. Adding a second comparison group of non-treated individuals, Roden et al. (2012) find improvements in verbal, but not visual memory. As highlighted by the authors, these papers are based on small and selective samples (50 to 75 observations), which may question the plausibility of the (implicitly made) common trend assumption. The effects on non-cognitive skills are also studied for JeKi. Nonte and Schwippert (2014) find no effects of the program on outcomes such as the self-concept of ability or the feeling of being integrated at school. However, their study also suffers from a small sample size and lacks data on the $65 \%$ of children who drop out of the program. Moreover, as they only use data from schools that were willing to participate in the evaluation, they are likely to overestimate the true effect. At the same time, Nonte and Schwippert (2014) only compare program participants to children in schools with an intensified sports curriculum, which might affect these skills as well.

This paper addresses this gap in the literature and answers two research questions related to the effects of the JeKi universal music education program in North Rhine-Westphalia, the most populous German federal state. First, I examine whether JeKi achieves its stated goal to increase access to music education for children from disadvantaged social backgrounds. I compare the effects of the program to those of a much simpler policy, which consists of reducing fees at public music schools. Second, I address the above-mentioned claims by policymakers and investigate whether JeKi also affects children's socio-emotional skills, as measured by the Strengths and Difficulties Questionnaire (SDQ), as well as their attitude toward school, teachers, fellow students and studying. To derive potential hypotheses on how JeKi might affect these traits, I describe a skill production model (Todd and Wolpin, 2003), in which school and family inputs can be more or less productive (Falck et al., 2015). The model illustrates that the potential influence of universal music education is composed of direct effects resulting from program participation, as well as indirect effects of crowding out alternative activities, which children would have carried out in absence of the program.

For the empirical estimations, I use a unique combination of three data sets. As the main data source, I use a repeated cross-section of 8- to 10-year-old children from the German SocioEconomic Panel (SOEP) and Families in Germany (FiD). For a random sample of German households, SOEP and FiD contain a variety of child development measures, as well as detailed information about the parents, including education and labor market participation (Schröder et al., 2013; Wagner et al., 2007). This individual-level data is geographically merged with statistics on the five closest primary schools, as well as the closest public music school.

To identify the causal effects of JeKi participation, I take advantage of the regional and temporal variation in the implementation of the program. Given that participating schools were not chosen randomly, I use a difference-in-differences estimator to eliminate potential time- 
constant unobserved heterogeneity between participating and non-participating schools. Moreover, to eliminate bias resulting from self-selection into JeKi schools, I estimate intention-totreat rather than actual treatment effects. To do so, I consider children as treated, if they live close to several schools offering the JeKi program in the year of school enrollment. Furthermore, I include not just numerous individual and regional control variables, but also county fixed effects.

My findings suggest that JeKi successfully reaches children who did not previously benefit from extracurricular music activities. The possibility to attend a primary school offering the JeKi program increases the likelihood of learning a musical instrument at age 9 by 30 percentage points among children from disadvantaged social backgrounds. This amounts to an increase of $115 \%$, given that, on average, only $26 \%$ of these children are musically active. Moreover, the possibility to participate in the JeKi program reduces behavioral problems and leads children to have a better relation to their school teacher. These effects are larger for boys and among children from wealthier households. Boys also appreciate school and studying more as a consequence of the JeKi program. All results are robust to variations in measurement and estimation method, as well as to sensitivity tests such as replacing the treatment by placebo reforms and measuring pre-treatment outcomes.

This paper adds to the literature by studying the effects of a large-scale publicly funded universal music education program on music activities and socio-emotional behavior. Contrary to the most closely related work by Nonte and Schwippert (2014), I use a random sample of students living in all areas of the program. The program is, therefore, analyzed in a random rather than self-selected subsample of participating primary schools. Moreover, I thoroughly discuss the potentially non-random selection of students and schools into the program, which is insufficiently taken account of in virtually all previous studies on such policies (Creech et al., 2013). My study proposes an empirical design that credibly identifies causal effects.

Moreover, I contribute to the more general literature on the effects of music training and non-formal education activities. Previous research on the effects of music is either experimental and uses data on self-selected study participants (Schellenberg, 2004), or analyzes observational data and faces the issue of non-random selection into music practice (e.g. Cabane et al., 2015; Covay and Carbonaro, 2010; Hille and Schupp, 2015; Southgate and Roscigno, 2009). By studying arguably exogenous variation in music participation in a randomly drawn observational data set, this study is the first to combine the advantages of both approaches.

Finally, I discuss effect heterogeneities with respect to socio-economic background, an important issue neglected in much of the existing research on music training, which is carried out in disciplines such as psychology, musicology and educational sciences.

The following section describes the JeKi program in more detail, followed by a discussion of its potential effects on non-cognitive skills (Section 3). Sections 4 and 5 present the data and method used for the empirical estimations. Section 6 discusses the results and their robustness with respect to measurement, estimation and identifying assumptions. 


\section{Institutional background: Music education in Germany and the JeKi program}

Learning a musical instrument is among the most popular education-oriented leisure time activities in Germany. Approximately $44 \%$ of 9 - to 12 -year-olds regularly play music. While many quit until early adulthood, $25 \%$ are still musically active between 18 and 25 years of age (Grgic and Züchner, 2013). Serious commitment to music is constantly increasing: the share of 17-year-olds taking musical instrument lessons and playing music at least weekly has risen from 10\% to 18\% between 2001 and 2012 (Hille et al., 2014). Even the substantial increase in the length of school days caused by a recent educational reform did not decrease the commitment to extracurricular musical activities (Dahmann and Anger, 2014; Grgic and Züchner, 2013).

Typically, musical instrument lessons in Germany take place on a voluntary basis and outside the general school system. ${ }^{1}$ A network of 929 public and at least 350 private music schools covers the entire country (VDM, 2014; BDPM, 2015). In addition to offering music lessons for individuals and groups, many of these cooperate with general schools to offer voluntary music projects in addition to the regular school curriculum. Partly due to the large expansion of allday schools, the number of such cooperations between music and primary schools increased by $63 \%$ from 2006 to 2013 (MIZ, 2014). In 2013, 4,347 of all 15,749 primary schools officially cooperated with public music schools (MIZ, 2014; Statistisches Bundesamt, 2015).

Despite the broad availability of music education both within and outside the general school system, participation in music activities depends highly on socio-economic background. Children with richer or more highly educated parents are considerably more likely to learn a musical instrument in their leisure time (Hille and Schupp, 2015). In multivariate regressions, parental education predicts participation in music activities more strongly than income (Hille et al., 2014). These socio-economic differences are, therefore, unlikely to solely reflect financial constraints. The German Association of Public Music Schools (Verband deutscher Musikschulen) requires its members to offer reduced fees for low-income families (VDM, 2011). Moreover, the educational package - introduced by the German federal government in 2011 - subsidizes sports club or music school membership for welfare recipients with 10 Euros per month (BMAS, 2015), an amount that is rather low in comparison with the average costs of extracurricular music education.

To make music education more accessible for children from all social backgrounds, several German federal states have established universal music education projects. North RhineWestphalia's JeKi - the project in the focus of this study - is currently the largest of these programs in Germany. It was first created as pilot project in 2007 and subsequently expanded to cover large parts of the Ruhr area. With 576 primary schools in 41 municipalities, approximately $20 \%$ of North Rhine-Westphalia's primary schools, JeKi reached its full scale in the $2011 / 12$ school year. $^{2}$

Participating primary schools were chosen as follows. If located in the program's target area, public music schools and municipalities could jointly apply for participation (JeKi-Stiftung,

\footnotetext{
${ }^{1}$ The regular school curriculum also includes music education, which may include some active music participation.

${ }^{2}$ In 2015, the federal state government expanded a modified version of JeKi - now called JeKits - to the entire federal state; see www.jedemkind.de.
} 
Figure 1 - Distribution of JeKi projects in 2011

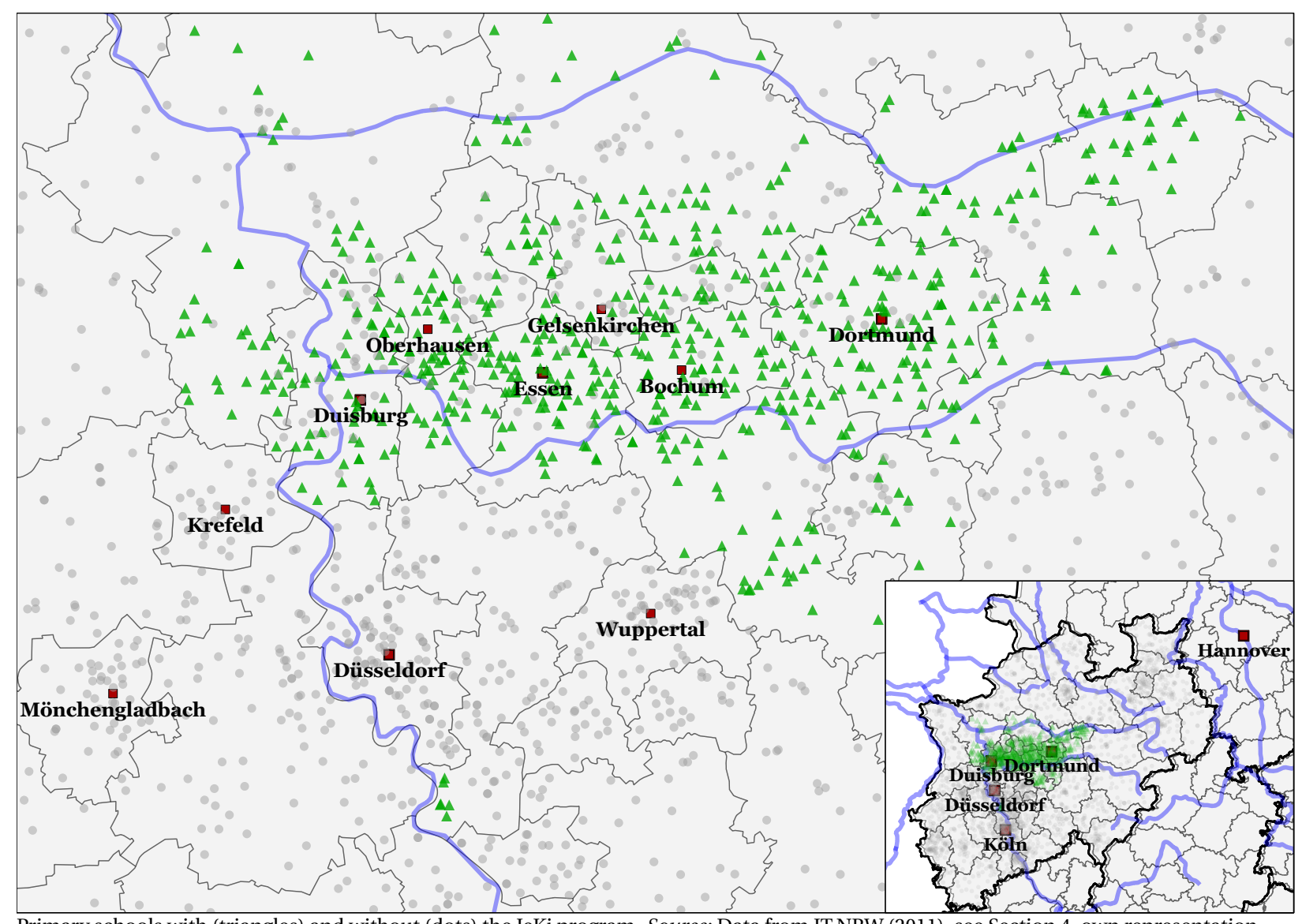

Primary schools with (triangles) and without (dots) the JeKi program. Source: Data from IT.NRW (2011), see Section 4, own representation.

2015). Among the submitted proposals, the program's coordinating body - the JeKi foundation - selected those that meet some previously defined "program standards" (JeKi-Stiftung, 2011). In other words, music schools and municipalities had to take the initiative to create JeKi projects. Only after their municipality had successfully applied could primary schools choose to participate in JeKi.

Figure 1 shows a map of North Rhine-Westphalia's primary schools. Primary schools participating in the JeKi project are represented by triangles, all other primary schools by dots. As described above, all of the federal state's JeKi schools are concentrated in the Ruhr area. However, the geographically concentrated distribution of projects is unlikely to simply capture a "Ruhr effect." Numerous schools in that area did not participate in the program, even after the program had reached its full scale in 2011. Moreover, JeKi's expansion between 2005 and 2011 did not follow any systematic geographical pattern.

JeKi involves its participants throughout primary school, from grade 1 to grade 4 (see Table 1). The program is in addition to the regular school curriculum. In the first year, students spend an additional hour each week with their regular primary school teacher covering basic musical topics such as rhythm and melody. Musical instrument lessons start in grade 2. Par- 
Table 1 - Description of "Jedem Kind ein Instrument" North Rhine-Westphalia

\begin{tabular}{|c|c|c|c|c|}
\hline \multicolumn{5}{|l|}{ COVERAGE BY YEAR } \\
\hline 2007 & 2008 & 2009 & 2010 & 2011 \\
\hline 34 municipalities & 41 municipalities & 42 municipalities & 42 municipalities & 42 municipalities \\
\hline 223 primary schools & 370 primary schools & 522 primary schools & 641 primary schools & 659 primary schools \\
\hline $\begin{array}{l}7,100 \text { students } \\
\text { (first-graders) }\end{array}$ & $\begin{array}{l}\text { 19,600 students } \\
\text { (first-graders) }\end{array}$ & $\begin{array}{l}27,700 \text { students } \\
\text { (first-graders) }\end{array}$ & $\begin{array}{l}31,150 \text { students } \\
\text { (first-graders) }\end{array}$ & $\begin{array}{l}32,754 \text { students } \\
\text { (first-graders) }\end{array}$ \\
\hline \multicolumn{5}{|c|}{ DESCRIPTION BY GRADE } \\
\hline \multirow{4}{*}{ Content } & Grade 1 & Grade 2 & Grade 3 & Grade 4 \\
\hline & $\begin{array}{l}\text { Basic concepts: } \\
\text { rhythm, melody }\end{array}$ & $\begin{array}{l}\text { Instrument lessons } \\
\text { (small group) }\end{array}$ & $\begin{array}{l}\text { Instrument lessons } \\
\text { (small group) }\end{array}$ & $\begin{array}{l}\text { Instrument lessons } \\
\text { (small group) }\end{array}$ \\
\hline & & & Ensemble lessons & Ensemble lessons \\
\hline & & & $\begin{array}{l}\text { Performance } \\
\text { (end of year) }\end{array}$ & $\begin{array}{l}\text { Performance } \\
\text { (end of year) }\end{array}$ \\
\hline Duration & $\begin{array}{l}1 \text { extra hour per } \\
\text { week with regular } \\
\text { school teacher }\end{array}$ & $\begin{array}{l}1 \text { extra hour per } \\
\text { week with music } \\
\text { school teacher }\end{array}$ & $\begin{array}{l}2 \text { extra hours per } \\
\text { week with music } \\
\text { school teacher }\end{array}$ & $\begin{array}{l}2 \text { extra hours per } \\
\text { week with music } \\
\text { school teacher }\end{array}$ \\
\hline \multirow[t]{2}{*}{ Participation } & Mandatory & Voluntary & Voluntary & Voluntary \\
\hline & Participation: $100 \%$ & Participation: $77 \%^{a}$ & Participation: $49 \%^{a}$ & Participation: $35 \%^{a}$ \\
\hline Costs (lessons) & Free & $\begin{array}{l}20 € / \text { month }^{b} \\
\text { (reduction possible) }\end{array}$ & $\begin{array}{l}35 € / \text { month }^{b} \\
\text { (reduction possible) }\end{array}$ & $\begin{array}{l}35 € / \text { month }^{b} \\
\text { (reduction possible) }\end{array}$ \\
\hline Costs (instruments) & Free & Free & Free & Free \\
\hline
\end{tabular}

Sources: JeKi-Stiftung (2014); JeKi-Stiftung (2013), own summary.

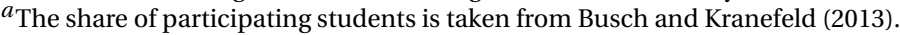

${ }^{b} 100 \%$ fee reductions for welfare recipients. $14 \%$ of the participants do not pay these fees (JeKi-Stiftung, 2008). 
ticipating children choose their preferred instrument and receive group lessons through grade 4. In the final two years, students additionally play in an orchestra and take part in concerts at the end of the school year. The choice of instruments offered can vary between schools, but it typically includes common string and wind instruments, as well as, in some cases, less typical ones such as mandolin or the Turkish bağlama (JeKi-Stiftung, 2011).

Participation in the first year of the program is mandatory. The program content of grades 2 through 4 is voluntary, with $70 \%$ of children taking at least one year of instrument lessons. In grades 3 and 4, participation drops to 49\% and 35\%, respectively (Busch and Kranefeld, 2013). Starting in grade 2, a monthly fee of 20 Euros is charged for participation, which increases to 35 Euros in grades 3 and 4 . However, welfare recipients are exempt from these charges. At this level, music lesson fees within JeKi are lower than what is charged by most public music schools (see Section 4). Instruments are loaned to children free of charge and can be taken home.

\section{Hypotheses: How does JeKi affect non-cognitive skill development?}

We can illustrate the potential effects of participating in the JeKi program using a simple model of skill production (Cunha et al., 2010; Todd and Wolpin, 2003), in which JeKi $(J)$ enters the skill production function in addition to the usual family and school inputs $(F$ and $S)$. Similar to Falck et al. (2015), each input can be of high $(h)$ or low $(l)$ productivity for skill development. The production of non-cognitive (and cognitive) skills $Y$ is thus described by the following equation:

$$
Y=f\left(S_{p}, F_{p}, J_{p}\right) \quad \text { with } \quad p \in\{h, l\}
$$

As described above, JeKi takes place in addition to the regular school curriculum and - given the fixed total amount of time - partly replaces family (or leisure time) inputs $F_{p}$. If we abstract from the school and family inputs received irrespective of program participation, the change in skill production due to JeKi $\left(\Delta_{J} Y\right)$ is:

$$
\Delta_{J} Y=f\left(J_{p}, \cdot\right)-f\left(F_{p}^{\prime}, \cdot\right)
$$

where family input $F_{p}^{\prime}$ is crowded out by the program. The treatment effect can therefore be decomposed into the direct effect of the program $\left(\partial f / \partial J_{p}\right)$ minus the skill production effect of the activity, which is crowded out $\left(\partial f / \partial F_{p}^{\prime}\right)$. I discuss each of these in the following.

The potential direct effect is activated by the program's two main components, which are playing a musical instrument and taking lessons in small groups. Learning to play a musical instrument is found beneficial for skill development in previous research. For example, the experimental study by Schellenberg (2004) shows that music training improves intelligence, at least in the short-run. Moreover, Hille and Schupp (2015) find that learning a musical instrument throughout childhood is associated with better school grades, as well as higher conscientiousness, openness and ambition. In their study, outcome differences between musically active and inactive adolescents remain positive and strongly significant even after controlling for a large number of parental background characteristics. Even compared to playing sports, music training is associated with better educational outcomes (Cabane et al., 2015). While there 
are many hypotheses according to which music affects further non-cognitive skills as well, no empirical study proves that this is the case (Winner et al., 2013).

Taking lessons in small groups might teach JeKi participants to closely interact with their peers and subordinate individual interests for the benefit of a common goal (Covay and Carbonaro, 2010). As a group activity, JeKi participation might therefore raise self-esteem and improve social skills (Lareau, 2011). More than in all other school subjects and many voluntary extracurricular activities, children participating in these small group lessons have to closely interact with their teacher, and might thereby improve their interpersonal skills. In addition, children might develop an improved sense of entitlement, which is the ability to speak up for something that one believes to deserve (Lareau, 2011).

As a third mechanism of program participation, we could consider the particular attention students receive from being part of a new and widely debated project. JeKi received substantial attention in the media and from politicians, with the hope that it would show "a positive transmission ... to the entire Federal Republic of Germany" (Kulturstiftung, 2015). Participating in a project, which generates such expectations, could positively or negatively affect students' attitude toward school.

According to the model described above, the average effect of JeKi participation also depends on how leisure time would have been spent in absence of the program. For example, Nonte and Schwippert (2014) compare JeKi participants to students attending schools with a reinforced sports curriculum and do not find any effects for the outcomes they study. JeKi could crowd out activities that are more or less (or just as) productive with respect to their effect on skill development. For example, non-participating schools might propose alternative programs involving music or sports. Alternatively, children might attend a sports club or music school on a voluntary basis, if they lack the possibility to take music lessons at their school within the JeKi program. On the other hand, the time spent with JeKi could have otherwise been spent by, for example, playing computer games or hanging out, with uncertain consequences for personality development.

The choice of leisure time activities strongly depends on socio-economic background. For example, Hille and Schupp (2015) find that, on average, children who learn a musical instrument outside of school have better educated and richer parents, who are more involved with their child's school success, who attend cultural events, and who carry out artistic activities themselves. Similar results are found for other activities (Cabane and Lechner, 2015). Therefore, I expect the average treatment effect of JeKi to be stronger for children from less favorable socio-economic backgrounds, because their counter-factual use of time is likely to be less productive for skill development than that of children from advantaged social backgrounds.

On the other hand, JeKi is voluntary after the first year. If children from less advantaged households are more likely to quit the program, effects are smaller for them compared to those who carry on through the end of grade 4. However, Busch and Kranefeld (2013) find that neither socio-economic characteristics nor migration background significantly predict whether children continue the program in grades 2 to 4 .

In addition to the direct and indirect effects described so far, we might expect interactions between JeKi participation with school and family inputs productivity, in the sense of the dynamic complementarity described by Cunha and Heckman (2007). For example, JeKi might 
increase students' motivation for school and, thereby, the effectiveness of learning. Moreover, positive experience in the JeKi program might encourage students to continue practicing their musical instrument after grade 4 . Depending on the productivity of the activity replaced, this could further contribute to the program's skill production effects.

Even though music education might affect various dimensions of cognitive and non-cognitive skills (Winner et al., 2013), the most relevant dimensions JeKi potentially improves are behavior, as well as the children's ability to get along with teachers and other children. The Strengths and Difficulties Questionnaire (SDQ) is particularly well-suited to assess such improvements (Goodman, 1997). I expect improvements in three of its five dimensions, which are related to social skills: a reduction in conduct problems, a reducation in peer problems, and increased pro-social behavior. The other two dimensions of the SDQ - hyperactivity and emotional symptoms - are probably less affected. Additionally, the JeKi program is likely to influence how children think about their school and whether they get along well with their teachers and peers.

These non-cognitive traits are important indicators of child development. A lack of social skills during childhood, especially with respect to adults, increases the likelihood of becoming a school dropout and of teenage pregnancy, while also negatively affecting adult labor market outcomes (Carneiro et al., 2007). Misbehavior in the classroom is also negatively related to educational attainment and earnings among young men (Segal, 2008, 2013), and is even considered as a possible source of the gender gap in academic achievement (Bertrand and Pan, 2013). Moreover, (classroom) misconduct correlates with lower conscientiousness (Ones et al., 2007; Roberts et al., 2003) and higher discount rates (Castillo et al., 2011), two important determinants of lower educational and labor market success.

\section{Data}

\subsection{Description of the data}

This study uses a unique data source, combining geo-coded information on primary schools and public music schools with individual-level data on 8- to 10-year-old children from the German Socio-Economic Panel (SOEP) and Families in Germany (FiD). By combining these data, I obtain information on each child's possibility to participate at the JeKi program or, alternatively, to attend music lessons at a nearby public music school. In the following, I describe the three data sets and how they are combined. For additional details, please refer to Appendix A.

First, I obtained a complete directory of North Rhine-Westphalia's primary schools for the year 2011, which is available from the federal state's statistical office (IT.NRW, 2011). It includes each school's address and total number of students. I created two additional variables indicating whether the school offers the JeKi program and, if applicable, the year it first participated. I received this information from the JeKi foundation, which coordinates the program. ${ }^{3}$ A very similar project in the municipality of Monheim ("Monheimer Modell") is also included in the analyses of this paper. None of the schools withdrew from the program during the relevant survey years.

\footnotetext{
${ }^{3}$ The list of JeKi schools can also be found on the program's website (www.jedemkind.de).
} 
Second, I use detailed statistics on all German public music schools from 2008 and 2012, as published in the statistical yearbook of German municipalities (Deutscher Städtetag, 2009, 2013). ${ }^{4}$ These contain variables such as the number of teachers and students (actual and fulltime equivalent), number of cooperations with general-education schools, fee revenues, revenues from state subsidies, as well as personnel expenditures.

The third, and main, data set contains individual-level data on 8- to 10-year-old children from two German household panel studies: the German Socio-Economic Panel (SOEP) and Families in Germany (FiD). ${ }^{5}$ The SOEP was created in 1984 and, as of 2015, surveys a random sample of approximately 12,000 German households every year (Wagner et al., 2007). FiD data has been collected since 2010 as part of a large evaluation of family-policies in Germany. It is closely related to the SOEP, but concentrates on poor families, families with many children, and single parents; it also includes cohort samples of families with children born between 2007 and 2010. FiD surveys approximately 4,000 households (Schröder et al., 2013). Due to a large overlap in questionnaire items, these studies can be jointly analyzed. ${ }^{6}$

With a household questionnaire, as well as a variety of individual questionnaires, SOEP and FiD survey information from all household members, covering many dimensions of life, such as education and labor market participation, family life, as well as personality traits, opinions and values. In addition, parents receive specialized questionnaires every two or three years, in which they provide information about their child's development, as well as their strategies and attitudes toward child education. These specialized questionnaires are an excellent data source for this paper, as they contain all the variables necessary to test the hypotheses developed above.

Given each child's place of residence, I calculate the distance to and merge the characteristics of the nearest public music school and the five nearest primary schools, using the data sets described above. Using the geo-coordinates of the household's postal code, I measure the geodesic distance to the exact geo-coded addresses of primary and music schools. ${ }^{7}$

The combined data set allows me to construct all of the variables needed for the empirical part of this study, as described in the following. To define treatments, I use the information on whether each of the closest five primary schools participates at the JeKi program, in which year they first offered the program, as well as the number of students at each school. Another treatment variable is based on the fee revenues and number of students at the closest public music school. The exact treatment definitions are explained below.

\footnotetext{
${ }^{4}$ The German Association of Public Music Schools (Verein deutscher Musikschulen) generously provided me these statistics in Excel files.

${ }^{5}$ Socio-Economic Panel (SOEP), data for years 1984-2013, version 30, SOEP, 2015, doi:10.5684/soep.v30.

${ }^{6}$ Starting from survey year 2014 (SOEP wave 31 and FiD wave 5), both data sets are distributed together under the label SOEP (v31).

${ }^{7} \mathrm{~A}$ specially secure procedure in accordance with strict German data privacy legislation allows on site researchers at DIW Berlin to merge geo-information with SOEP households using their addresses at the street-block level (Goebel and Pauer, 2014). An application of this procedure is in Bauernschuster et al. (2014). However, due to a substantial amount of missing geo-coordinates, I decided to reduce precision and merge distances at the postal code level. As the aim is to select the primary and music schools individuals are most likely to attend, this degree of precision is probably sufficient.
} 
This study examines two types of outcome variables. The first is related to JeKi's primary goal of providing children from disadvantaged backgrounds with access to music education. To assess whether this happens, I use two variables from the SOEP and FiD household questionnaire that ask parents whether their children attend a music club at school, and whether they play music outside of school. SOEP households have received these questions biannually since 2004, while FiD households receive them every year (2010 to 2013 in our data). As parents of JeKi participants might categorize their child's musical activities as being at or outside school, I created a combined variable indicating whether a child plays music at or outside of school. In one robustness check, I examined whether the definition of children's music activities matters for the results (see Section 6).

Further outcomes are taken from SOEP and FiD's parent-child questionnaires, which measure the two categories of non-cognitive skills that might be affected by the JeKi program. These include the Strengths and Difficulties Questionnaire (SDQ), as well as the child's attitude toward school as reported by parents in the year of their child's eighth and tenth birthday. ${ }^{8}$ The SDQ describes whether children experience emotional symptoms, conduct problems, hyperactivity, peer problems, and to what extent they show pro-social behavior (Goodman, 1997). Each of these five dimensions is assessed with two to five items, in which parents rate their approval to descriptions of the child's behavior on a 3-point Likert scale (Richter et al., 2013). Most studies take the sum of the difficulties (all variables except pro-social behavior) as a measure of SDQ. In addition, I also study each dimension separately.

The variables related to the attitude toward school each consist of one questionnaire item. On a 4-point Likert scale, parents were asked to judge whether their children (1) like to go to school; (2) like to study; (3) get along well with teachers; (4) get along well with classmates; and (5) follow lessons well. Table A.7 provides the exact wording of each item.

All dimensions of the SDQ and the attitude toward school were coded such that a higher value indicates a better outcome. Moreover, all variables were normalized to have mean 0 and a standard deviation of 1 within the control group. In addition, I created an aggregate index that is a weighted average of all non-cognitive outcome dimensions described above, following an approach suggested by Anderson (2008), with the aim of reducing false rejections of the null hypothesis due to multiple inferences. The aggregate index is an average, in which each normalized outcome is weighted by the inverse of its covariance matrix with respect to all other outcomes. With other words, variables receive a higher weight if they add more information to the aggregate index.

All outcome variables are measured when the child was 8 and 10 years old. As not everyone is part of the sample at both ages, and to increase the sample size in the baseline specification, I aggregated both age groups. To do so, I measured the outcome at age 10 if available, otherwise at age $8 .^{9}$ However, the results were also analyzed separately for the sample of 8- and 10-yearolds.

Covariates are mainly taken from the individual and household questionnaires of the child's parents. I observe gender, migration background and the age of school enrollment for the child.

\footnotetext{
${ }^{8}$ In the SOEP, the relevant variables are only available for age 10.

${ }^{9}$ In this aggregated group, outcomes were measured at age 8 for about a third of the children.
} 
Moreover, covariates include the mother's age at birth, upper secondary school and university education of the parents, as well as their combined weekly work hours. In addition, I control for household income, household size, whether the child lives in a single-parent home, and whether the household lives in a rural or urban area. To take into account regional heterogeneities, I include characteristics of the county of residence, which are available from the Federal Institute for Research on Building, Urban Affairs and Spatial Development (BBSR, 2015). These include GDP, household income, child poverty and youth unemployment rate, level of education, share of foreign students, as well as the share of children in daycare, all measured in 2012. Table A.7 presents the full list of control variables and how they are measured.

\subsection{Estimation sample and treatment definitions}

The sample used in this study consists of all children for whom all outcomes in at least one of the two outcome groups - music activities or non-cognitive skills - are observed. Therefore, to be in the sample, parents must have answered either the household or the parent-child questionnaires noted above. Being in the sample depends on birth year and questionnaire design, which are unrelated to any of the treatment or outcome variables. ${ }^{10}$ Restricting the sample to North Rhine-Westphalia, the final data contains 1138 children born between 1997 and 2005 . Among these, I have information on music activities for 997 and the non-cognitive skills for 689 children. Results are robust to only examining the 548 individuals with valid observations for all outcomes in both categories.

For $7 \%$ of the observations, I do not observe the parents' work hours. The information for the mother's age and the child's migration background are missing in $2 \%$ and $1 \%$, respectively, of the cases. In addition, characteristics of the local public music school are missing for almost $3 \%$ of the sample. ${ }^{11}$ Given the small sample size and the importance of these control variables, I recoded missing observations to 0 for binary and to the mean for continuous variables, and included four missing indicators in all estimations (one indicator for each of the first three variables, and a fourth indicator for at least one missing music school characteristic). However, all estimations are robust to restricting the sample to observations without any missing covariate. In this case, the sample sizes are 881 for music activities and 603 for non-cognitive skills.

The treatment group consists of children who had the possibility to participate in the JeKi universal music education program. To avoid bias resulting from selection into specific primary schools, I define treatment based on the probability to take part in the JeKi program. For that purpose, I assume that children attend one of the five closest primary schools within a radius of $5 \mathrm{~km} .{ }^{12}$ Among these schools, I calculate the share of students having access to the JeKi program in the year of school enrollment. I consider children as treated if that share is at least $50 \%$. Table 2 explains the exact steps of how the treatment was defined. In various robustness

\footnotetext{
${ }^{10}$ I lose $5 \%$ of the observations due to missing outcomes in the non-cognitive skills sample. Moreover, I lose $2 \%$ of the observations due to a missing treatment status. See Table A.6 for details on how the sample was constructed.

${ }^{11}$ To prevent missing values on the household income, I use the first plausible value of the imputed variable contained in the SOEP and FiD data distribution.

${ }^{12}$ See Section 5 for a discussion of that assumption. I chose a cutoff of $5 \mathrm{~km}$, because no child in the sample lives more than $5 \mathrm{~km}$ away from the closest primary school.
} 
Table 2 - Construction of treatment variables (main definitions ${ }^{a}$ )

\begin{tabular}{|c|c|}
\hline \multicolumn{2}{|l|}{ Treatment 1: JeKi share above $50 \%$} \\
\hline Steps carried out & Details \\
\hline $\begin{array}{l}\text { 1. Identify potential primary } \\
\text { schools (target schools) }\end{array}$ & $\begin{array}{l}\rightarrow \text { select the } 5 \text { primary schools closest to household's place of residence } \\
\rightarrow \text { delete schools at a distance of more than } 5 \mathrm{~km}\end{array}$ \\
\hline $\begin{array}{l}\text { 2. Check whether JeKi was avail- } \\
\text { able in school enrollment year }\end{array}$ & $\begin{aligned} & \rightarrow \text { do target schools have JeKi program? (if not: JeKi not available) } \\
& \rightarrow \text { check whether JeKi was created in the year of school enrollment or be- } \\
& \quad \text { fore (JeKi available), or in a later year (JeKi not available) }\end{aligned}$ \\
\hline $\begin{array}{l}\text { 3. Calculate JeKi share among } \\
\text { target school students }\end{array}$ & $\begin{array}{l}\rightarrow \text { add the total number of students at each of the target schools offering } \\
\text { JeKi in the year of school enrollment } \\
\rightarrow \text { divide this number by the total number of students in all target schools }\end{array}$ \\
\hline 4. Transform into binary variable & $\begin{array}{c}\rightarrow 1 \text { if JeKi share } \geq 50 \% \\
0 \text { if JeKi share }<50 \%\end{array}$ \\
\hline
\end{tabular}

Treatment 2: Music school fees below 33rd percentile

\begin{tabular}{ll}
\hline Steps carried out & Details \\
\hline 1. Calculate fees for each school & $\begin{array}{l}\rightarrow \\
\text { "total fee revenues" / "total number of students" for each music school } \\
\text { (average fees, ignores potential income-based reductions) }\end{array}$ \\
$\begin{aligned} \rightarrow \text { 2. Calculate 33rd percentile } & \text { among all music schools of North Rhine-Westphalia } \\
\text { 3. Transform into binary variable } \rightarrow & \text { Identify the public music school closest to the child's home (target mu- } \\
& \text { sic school) } \\
\rightarrow & 1 \text { if target music school fees }<33 \text { rd percentile within federal state } \\
& 0 \text { if target music school fees } \geq 33 \text { rd percentile within federal state }\end{aligned}$ \\
\hline
\end{tabular}

a Alternative treatment definitions were tested as robustness checks.

checks, I vary this definition and consider children as treated if the share of JeKi students is at least $5 \%$ or take the JeKi share as a continuous treatment variable. In further variations, I also consider schools farther than $5 \mathrm{~km}$ away, ignore schools outside the municipality, and weight schools by distance to the child's home. Please refer to Section 6, as well as Appendix B.3 for more details.

Figure 2 describes the sample size by treatment status for each school enrollment year in the overall sample of individuals with observations for at least one outcome group. The sample is split into JeKi and non-JeKi areas, given that the estimations rely on difference-in-differences (see section 5). Non-treated individuals in JeKi areas attend schools that offer the JeKi program in later years, but not the year they enrolled, while treated individuals attend schools that already offer the program. Figure 2 shows that the first JeKi programs were introduced in 2007. In 2009, only 5 individuals in the sample attended schools that would start the program in a later year. Figure A.5 shows the same graph for each outcome sample separately.

As described in Section 3, the potential effects of JeKi depend on the counter-factual use of time. Therefore, I define an alternative treatment, representing one possible outside option for learning a musical instrument. I define children to receive the alternative treatment, if the public music school closest to their home charges fees in the lowest third of the public North 
Figure 2 - Number of observations in treatment and control group for each school enrollment year

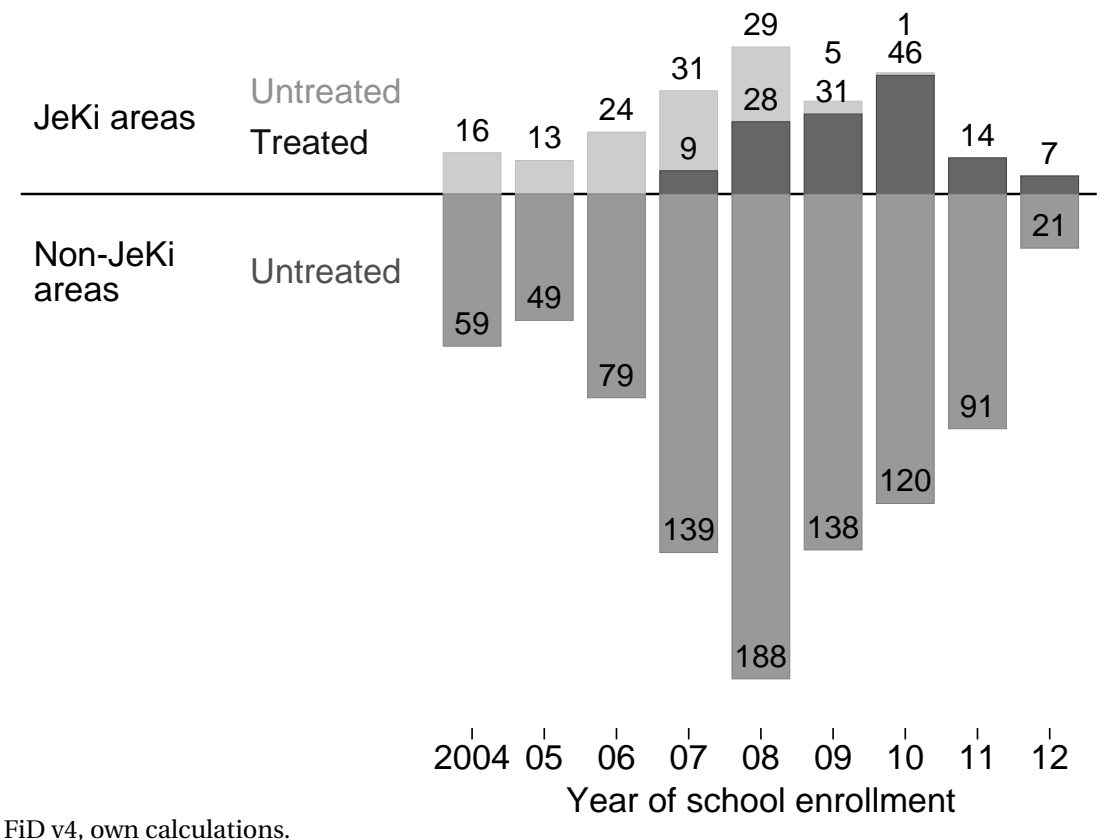

Source: SOEP v30 and FiD v4, own calculations.

Rhine-Westphalia music schools. This is a rather crude measure of music school fees, given that the German association of public music schools asks its members to request lower fees from low-income families (VDM, 2011). As described above, the data on public music schools only contain fee levels for 2008 and 2012. I assigned the earlier fee level to all children born before 2000, while those born in 2000 or later are assumed to pay 2012 fees. Given that the treatment variable is binary (fee levels below the 33rd percentile), the treatment status is not sensitive to such assignment decisions. Few public music schools changed their fee levels or their rank in the fee distribution between 2008 and 2012. Table 2 explains the details of how the music school fee treatment variable is constructed. As with JeKi participation, I propose various variations of this treatment, which are described in detail in Section 6, as well as Appendix B.3.

To model the trade-off between JeKi and music lessons at the local music school even more explicitly, I define a third treatment, combining both of the previously described variables. The combined treatment can take three values: (1) the JeKi share is above $50 \%$, (2) the JeKi share is below $50 \%$ and music school fees are below the 33rd percentile of the fee distribution and (3) the JeKi share is below $50 \%$ and music school fees are above the 33rd percentile. Similar to the multiple treatment setting in Lechner (2001), I compare the differential effects by performing pairwise comparisons.

Average music school fees in North Rhine-Westphalia vary between 13 and 59 euros per month. Approximately $77 \%$ of the children who have access to JeKi live close to a music school that charges low fees (see Figure A.6). This results from the fact that public music schools are the primary school's cooperating partner for most of the JeKi projects. JeKi participants therefore count toward the total number of students at the music school. As JeKi lessons are partly financed through public subsidies, they contribute less to the music school's fee revenues, mak- 
ing their average fees decline. Nonetheless, many public music schools charge fees at a similarly low level, even though they do not act as a cooperating partner for JeKi. At the same time, $23 \%$ of the JeKi projects were implemented in areas, where the public music school charges relatively high fees.

Further summary statistics on all treatment, outcome and control variables, as well as detailed descriptions of how each variable was constructed, are found in Appendix A.

\section{Empirical strategy}

\subsection{Identification of causal effects}

This paper examines the causal effects of the JeKi program on music activities and noncognitive skills. Moreover, I estimate how low music school fees affect participation in music lessons. The identification of causal effects is complicated by the fact that neither the schools that offer the JeKi program nor the program participants themselves are chosen randomly. The same is true for the alternative treatment of low public music school fees, which might be determined as a function of local demand. Such non-random selection biases the estimated treatment effects if unobserved factors affect the individual's assignment to the treatment group and simultaneously influence the outcomes of interest.

Endogeneity might occur both at the school and the individual level. On the one hand, both music school fees and JeKi participation might be driven by unobserved heterogeneity between primary or music schools. For example, we would overestimate the true effect of JeKi, if the program was systematically implemented by particularly motivated school principals. These school principals might be better able to run their schools. In addition to implementing JeKi, they might, for example, hire better quality teachers or provide better learning environments. Our estimates would wrongly count these additional quality inputs as causal effects of the JeKi program. Conversely, we might underestimate the true effect of JeKi, because nonparticipating schools might propose alternative activities involving music, sports, theater or any other activity. Rather than comparing schools with and without JeKi, we would compare JeKi schools to those with alternative programs, which might be beneficial as well.

Simultaneity could be a second school-related reason for biased estimates of the treatment effect. As the program is systematically implemented in poorer areas (see Section 6), we are likely to underestimate its effects due to systematic differences in the ability of the student body. The same is true for public music school fees, which are also more likely to be low in poorer areas.

On the other hand, selection bias could result from individual unobserved heterogeneity. For example, motivated parents could enroll their children at JeKi schools, or even move to JeKi areas. Similarly, parents could send their children to less expensive music schools farther away from home. Therefore, the estimated treatment effects would capture parental engagement, which benefits child development irrespective of music activities.

I take these potential sources of endogeneity into account by estimating intention-to-treat rather than treatment effects. Moreover, I exploit the regional variation of both the JeKi program and low music school fees. For the former, I can even take advantage of the temporal variation of program implementation and estimate difference-in-differences. Finally, I include 
a large number of individual- and county-level control variables, as well as county fixed effects. In the following, I describe how these approaches address the endogeneity problem, thus allowing for the identification of causal effects of both treatments.

To reduce the bias resulting from non-random selection into treatment by individuals, the results of this paper describe intention-to-treat effects of JeKi and low music school fees. Given that participation beyond the first year of the JeKi program is voluntary, actual enrollment would be an endogenous treatment, which could be related to individual-level characteristics that also affect the outcomes. I therefore consider children as treated, if they have the possibility to participate, irrespective of whether they actually sign up. As described in Section 4, individuals belong to the treatment group if the share of students with access to the JeKi program in the five primary schools closest to child's home (within a radius of $5 \mathrm{~km}$ ) in the year of school enrollment is greater than $50 \%$. Similarly, living near a public music school that charges low fees can be considered as an intention-to-treat effect, because low fees only affect children in the sense that they provide a higher incentive to sign up for music classes.

The effect of having the possibility to learn a musical instrument - the "intention to treat" - is relevant for two reasons. First, it is the parameter policymakers can influence. Policymakers need to know whether creating a voluntary program has positive effects, and these depend on whether individuals actually sign up. Second, the intention-to-treat effect includes the potentially negative effects for non-participants and thereby describes a more complete picture of the program's overall effects. Some individuals might suffer from non-participation. They could receive a lower quality education if schools decide to concentrate their resources on program participants. Moreover, they could feel excluded and, consequently, reduce effort. The intention-to-treat effect takes such potential peer effects on non-participants into account by aggregating the effect of participation and non-participation among all individuals who have the possibility to participate.

While estimating intention-to-treat effects, I cannot rule out the possibility that parents from particular socio-economic backgrounds specifically select JeKi schools for their children in areas where only some of the five neighborhood schools offer the program. ${ }^{13}$ If this is the case, my estimations capture the treatment effect of JeKi on those who choose to participate. With other words, individual selection into schools within neighborhoods would lead me to estimate average treatment effects on the treated rather than average treatment effects.

In addition to focusing the estimates on the "intention to treat", I use regional variation to identify causal effects. As described in Section 2, JeKi exists in some areas of North RhineWestphalia and not in others. Similarly, average monthly fees at the federal state's public music schools range from about 12 to 60 Euros (see Section 4). Assignment to the treatment group therefore depends on the individual's place of residence.

Still, both treatments are not randomly distributed across regions (see Section 6). Therefore, I further refine the estimations by additionally taking advantage of temporal variation. For JeKi, this amounts to a difference-in-differences estimator. As described in Section 2, the program was gradually implemented starting in 2007 until it reached its full level of expansion in 2011.

\footnotetext{
${ }^{13}$ In the sample, $15 \%$ of the children are surrounded by some schools with and some without the JeKi program; only $4 \%$ have access to the program in all of the five surrounding schools.
} 
Given that I observe individuals in JeKi areas before and after the program was implemented, I can take into account time constant unobserved differences between areas with and without JeKi. To do so, I estimate the effect of having access to JeKi in the year of school enrollment and additionally control for time fixed effects, as well as a dummy for JeKi areas. This dummy is set to " 1 " if the "JeKi share" is higher than $50 \%$ in any year, even if JeKi is only implemented in a later year and the child thus not treated.

For the other treatment of low music school fees, a difference-in-differences estimator would theoretically be possible as well. I observe public music school fees in 2008 and 2012, and merge the information for the year that is more relevant for each child (see Section 4). By including music school fixed effects, I would identify treatment effects from the variation that arises if certain schools change their fees. However, music school fees were relatively stable between both years. Given that the treatment is defined as a binary variable indicating whether the fees were below average, only very few schools changed treatment status. To account for potential music school-specific unobserved heterogeneity, I therefore included various music school characteristics as control variables. These contain information on the number of students and school cooperations, total revenues and the share of federal state subsidies, as well as the share of students enrolled in basic classes, instrument and ensemble lessons. Finally, to capture any remaining unobserved heterogeneity, I include county fixed effects, as well as covariates describing characteristics of the child, the parents and the county of residence. Please refer to Section 4, as well as Appendix A for further details and summary statistics of all control variables.

With the identification strategy described so far, I identify causal effects under two assumptions. First, I need to assume a common trend, according to which JeKi and non-JeKi areas would have evolved similarly with respect to the outcomes, had the JeKi program not existed. Second, I assume that families did not move in order to live closer to a JeKi school. North Rhine-Westphalia abolished primary school catchment areas in 2008, allowing parents to freely choose their child's primary school. However, numerous exceptions were granted even before 2008, inter alia to facilitate leisure time activities for children (Riedel et al., 2010). Moreover, the student composition with respect to migration background of the state's primary schools has not changed due to the reform (Makles and Schneider, 2015). Given the free choice of primary schools, as well as the numerous possibilities to learn a musical instrument in all regions of Germany, I argue that families are unlikely to move for the purpose of having access to the JeKi program or living closer to a cheap public music school. Whether these assumptions are plausible is discussed in Section 6, along with some robustness tests.

\subsection{Estimation}

In comparison to semi-parametric methods, such as propensity score matching, OLS can lead to biased coefficients due to the necessity to impose functional form restrictions. This is particularly true if the distribution of covariates differs strongly between treatment and control group (Imbens, 2015). However, to obtain correct standard errors for coefficients obtained by a propensity score matching estimator, one needs to take into account the two-step estimation procedure. Even though an analytical approximation exists, standard errors are usually 
estimated from bootstrap replications (Huber et al., 2015). Given the small sample size, and especially the small number of treated individuals (94 out of 689 in the smallest sample for noncognitive skills), the bootstrap is not reliable in drawing samples with sufficient variation in the treatment status. Therefore, and in order to be in line with most other papers using differencein-differences estimators, the main specifications were estimated using ordinary least squares (OLS). In any case, the distribution of covariates is rather similar between treatment and control group. However, the results are robust to changing the estimation procedure to propensity score matching or entropy balancing.

In the main specification, the effect of JeKi on outcome $Y$ is estimated using the following estimation equation:

$$
Y_{i}=\beta_{1} T_{i}+\beta_{2} G_{i}+\tau_{\text {year }}+\beta_{3} X_{i}+\beta_{4} X_{\text {county }}+\eta_{\text {county }}+\varepsilon_{i}
$$

The first three terms on the right-hand side correspond to the standard difference-in-differences estimator. $\beta_{1}$ is the coefficient of interest, describing the effect of treatment $T_{i}$, indicating whether the share of children with access to the JeKi program in the nearest primary schools is above $50 \%$ in the year of school enrollment. With other words, it is an interaction between living in a treatment region and being actually treated. $\beta_{2}$ captures the time-constant unobserved heterogeneity between JeKi and non-JeKi areas, given that $G_{i}$ is an indicator of whether the child is surrounded by schools, in which at some point in time the share of students having access to the JeKi program is or will be above $50 \%$. $\tau_{y e a r}$ are fixed effects for the year in which individual $i$ enters primary school. They cover cohort effects common to treatment and control group. The remaining terms in the estimation equation contain the control variables described above: characteristics of child and parents $\left(X_{i}\right)$, county-level covariates $\left(X_{\text {county }}\right)$, as well as county fixed effects $\left(\eta_{\text {county }}\right)$. In all estimations, standard errors are clustered at the county level.

\section{Results}

\subsection{Effects of the JeKi program on access to music education}

JeKi was created with the goal of providing access to music education, in particular, for children from less favorable social backgrounds. Table 3 shows that JeKi was indeed implemented in poorer regions. Households in areas with a JeKi coverage of at least $50 \%$ earn on average 170 Euros less every month than those situated elsewhere. The child poverty rate in JeKi areas is almost 10 percentage points and the share of foreign pupils almost 4 percentage points higher. On the individual level, these differences are similar. Only $23 \%$ of the children in JeKi areas have parents with a university degree, compared to $29 \%$ of the children living elsewhere. ${ }^{14}$ The last four columns of Table 3 show that music school fees are lower in poorer areas as well. However, these differences are only about half the size as those for JeKi.

\footnotetext{
${ }^{14}$ Differences are less significant for individual than for county characteristics, simply due to the fact that the variation is at the individual level, while in the upper part of Table 3 the characteristics only vary across the 55 counties of North Rhine-Westphalia.
} 
Table 3 - Individual and county-level background characteristics by treatment group status (in \%)

\begin{tabular}{|c|c|c|c|c|c|c|c|c|}
\hline & \multicolumn{4}{|c|}{ JeKi share $>50 \%$} & \multicolumn{4}{|c|}{$\begin{array}{l}\text { Music school fees } \\
\text { in lowest third }\end{array}$} \\
\hline & No & Yes & Diff. & $p$ & No & Yes & Diff. & $p$ \\
\hline \multicolumn{9}{|l|}{ County-level characteristics } \\
\hline Av. monthly HH income/person (euros) & 1739 & 1568 & -171 & 0 & 1724 & 1651 & -73 & 2 \\
\hline Yearly GDP/person (1000 euros) & 34.0 & 30.9 & -3.0 & 26 & 33.5 & 32.9 & -0.5 & 79 \\
\hline Share students with Abitur (\%) & 36.3 & 36.6 & 0.3 & 78 & 36.7 & 35.6 & -1.1 & 22 \\
\hline Share students without degree (\%) & 4.8 & 6.0 & 1.2 & 0 & 4.9 & 5.4 & 0.5 & 5 \\
\hline Youth unemployment rate (\%) & 19.6 & 18.7 & -0.9 & 9 & 19.6 & 18.9 & -0.7 & 5 \\
\hline Share foreign pupils (\%) & 7.9 & 11.7 & 3.8 & 0 & 8.2 & 9.9 & 1.7 & 4 \\
\hline Child poverty rate $(\%)$ & 15.9 & 25.4 & 9.6 & 0 & 16.7 & 20.8 & 4.1 & 2 \\
\hline \multicolumn{9}{|l|}{ Individual-level characteristics } \\
\hline Monthly net HH income (euros) & 3181 & 2947 & -234 & 13 & 3183 & 3012 & -171 & 25 \\
\hline Parent with Abitur & 33.4 & 34.3 & 0.9 & 85 & 35.2 & 30.1 & -5.1 & 18 \\
\hline Parent with university degree & 29.4 & 23.2 & -6.2 & 12 & 30.2 & 23.4 & -6.8 & 6 \\
\hline Migration background (child) & 35.6 & 33.1 & -2.6 & 51 & 34.5 & 36.2 & 1.7 & 67 \\
\hline Only one parent at home & 14.8 & 16.9 & 2.1 & 40 & 14.6 & 16.7 & 2.1 & 34 \\
\hline $\mathrm{Nb}$ of children under 16 in $\mathrm{HH}$ & 2.6 & 2.6 & 0.0 & 94 & 2.5 & 2.7 & 0.2 & 6 \\
\hline
\end{tabular}

Source: SOEP v30 and FiD v4, own calculations. T-test of differences between selected covariates in treatment and control groups for both treatments. Standard errors are clustered at the county level.

Given that participation in the JeKi program is voluntary after the first year, merely implementing JeKi in poorer areas is not sufficient to ensure that children from disadvantaged backgrounds actually start learning a musical instrument. To further investigate this hypothesis, Table 4 shows the causal effects of access to the JeKi program using the identification strategy described in the previous section. The first part of the table investigates the effects of JeKi on music activities and compares them with those of the alternative policy of low music school fees. Column (1) displays the effects for the full sample, while columns (2) to (6) show subgroup analyses, distinguishing children by their socio-economic status and gender. Each cell represents a distinct regression. Coefficients display the effect of access to the JeKi program (except for the second line, where the treatment is low music school fees) on the outcome indicated in the first column. Sample sizes by treatment and control group, as well as the R-square for each regression are presented in Tables B.15 and B.16.

The first part of Table 4 shows that JeKi can be considered successful with respect to its primary objective. On average, having access to the JeKi program increases the likelihood to play a musical instrument at or outside of school at the age of 9 by 14 percentage points (first row of column 1). With an average of $36 \%$ being musically active at that age, this amounts to an increase of almost $40 \%$. The effect is considerably stronger for girls than for boys (columns 2 and 3). Music schools that charge fees in the lowest third of the fee distribution increase the likelihood of playing a musical instrument to a lower extent, by 10 percentage points (row 2).

Examining the heterogeneity of these effects by socio-economic status illustrates that the JeKi program is much more successful than low music school fees in reaching disadvantaged children. While both affect children from poorer families (column 4), the effect of JeKi is partic- 
ularly strong, reaching 30 percentage points. This amounts to an increase of $115 \%$, if we consider that on average only $26 \%$ of the children from households with a below-median income are musically active. Table 4 distinguishes according to household income, but the effects are similar (albeit somewhat smaller) when defining socio-economic status by parental education or migration background (see Table B.18). This is consistent with the hypothesis that children from richer households might engage in music activities even in absence of the JeKi program. Children from poor families might be less affected by variations in music school fees, as they are supposed to receive fee reductions in any case, as stated in the governing rules of the German association of public music schools (VDM, 2011).

Table 4 - Effects of access to the JeKi program (OLS estimates)

\begin{tabular}{|c|c|c|c|c|c|c|c|c|c|c|}
\hline & \multirow{2}{*}{\multicolumn{2}{|c|}{$\begin{array}{c}\text { Full sample } \\
\text { (1) }\end{array}$}} & \multicolumn{4}{|c|}{ by gender } & \multicolumn{4}{|c|}{ by household income } \\
\hline & & & \multicolumn{2}{|c|}{$\begin{array}{c}\text { Male } \\
(2)\end{array}$} & \multicolumn{2}{|c|}{$\begin{array}{c}\text { Female } \\
\text { (3) }\end{array}$} & \multicolumn{2}{|c|}{ < median } & \multicolumn{2}{|c|}{$>$ median } \\
\hline & Diff. & $p$ & Diff. & $p$ & Diff. & $p$ & Diff. & $p$ & Diff. & $p$ \\
\hline \multicolumn{11}{|l|}{ MUSIC ACTIVITIES } \\
\hline Plays music & 0.14 & 2 & 0.06 & 52 & 0.20 & 3 & 0.30 & 0 & 0.04 & 61 \\
\hline \multicolumn{11}{|c|}{ Alternative treatment: Music school fees in lowest third } \\
\hline Plays music & 0.10 & 5 & 0.17 & 1 & 0.03 & 68 & 0.16 & 5 & 0.06 & 35 \\
\hline Sample size & 997 & & 502 & & 495 & & 443 & & 554 & \\
\hline \multicolumn{11}{|c|}{ NON-COGNITIVE SKILLS } \\
\hline \multicolumn{11}{|c|}{ Strengths and Difficulties Questionnaire } \\
\hline No emotional symptoms & -0.04 & 84 & 0.02 & 91 & -0.21 & 49 & -0.03 & 92 & -0.19 & 51 \\
\hline No conduct problems & 0.40 & 3 & 0.38 & 14 & 0.59 & 9 & 0.26 & 17 & 0.59 & 8 \\
\hline Not hyperactive & 0.15 & 37 & 0.28 & 33 & 0.32 & 29 & -0.06 & 78 & 0.34 & 26 \\
\hline No peer problems & -0.03 & 86 & -0.23 & 49 & -0.03 & 88 & -0.10 & 73 & 0.07 & 85 \\
\hline Pro-social behavior & 0.19 & 33 & 0.03 & 92 & 0.18 & 62 & 0.21 & 51 & 0.28 & 44 \\
\hline \multicolumn{11}{|l|}{ Attitude towards school } \\
\hline Likes to go to school & 0.25 & 14 & 0.53 & 5 & -0.06 & 84 & 0.23 & 35 & 0.21 & 52 \\
\hline Likes to study & 0.34 & 12 & 0.94 & 0 & 0.02 & 95 & -0.03 & 95 & 0.65 & 1 \\
\hline Follows lessons well & 0.04 & 86 & 0.23 & 63 & 0.09 & 75 & -0.59 & 17 & 0.71 & 0 \\
\hline Gets along well... & & & & & & & & & & \\
\hline ...with classmates & 0.14 & 46 & 0.00 & 99 & 0.09 & 76 & 0.26 & 34 & 0.16 & 54 \\
\hline ...with teacher & 0.27 & 2 & 0.52 & 7 & -0.02 & 95 & 0.03 & 93 & 0.50 & 5 \\
\hline \multicolumn{11}{|c|}{ Combined non-cognitive skills scores } \\
\hline Non-cog. skills (aggregate) & 0.17 & 4 & 0.29 & 8 & 0.10 & 44 & -0.00 & 97 & 0.34 & 2 \\
\hline Difficulties (from SDQ) & 0.18 & 41 & 0.19 & 51 & 0.26 & 42 & 0.03 & 90 & 0.31 & 41 \\
\hline Sample size & 689 & & 341 & & 348 & & 327 & & 362 & \\
\hline
\end{tabular}

Source: SOEP v30 and FiD v4, own calculations. Each cell is a separate OLS regression estimating how access to the JeKi program affects the outcome denoted in the first column. Please refer to Section 4 for more details on the treatment definition. All regressions are estimated using difference-in-differences, and additionally control for individual and regional characteristics, as well as county fixed effects. Effects of the alternative treatment (music school fees in lowest third) are estimated with standard OLS (no difference-in-differences), additionally including music school characteristics as control variables. Standard errors are clustered at the county level. The number of observations, as well as the R-squares for each regression are displayed in Tables B.15 and B.16. "Plays music" is a binary variable indicating whether the child played a musical instrument at or outside school at age 9 . All other outcome variables are normalized with mean 0 and a standard deviation of 1 within the control group. The exact definitions of all outcome and control variables are given in Table A.7. 


\subsection{Effects of the JeKi program on non-cognitive skills}

As stated in the introduction, many policymakers claim that JeKi is an important policy not only for providing access to music education, but also for the personality development and educational success of its participants. According to the characteristics of the program (small group lessons in addition to the regular school curriculum), JeKi is particularly likely to affect social skills and school attitude, given that children learn to interact with peers and teachers in groups that are much small than regular school classes (see section 3). The second part of Table 4 shows the effects of the JeKi program on these and other dimensions of the Strengths and Difficulties Questionnaire, as well as the attitude toward school.

Overall, JeKi seems to positively affect most items from the Strengths and Difficulties Questionnaire and the attitude toward school, even though standard errors are often too large to yield significant coefficients. For the full sample, two effects are highly significant: Children with access to the JeKi program have fewer conduct problems and get along better with their teacher. In both cases, improvements are very large between one third and one half of a standard deviation. Effects of this size seem plausible, given that despite of measuring intention-totreat effects, most children living near JeKi schools actually follow the JeKi program. Nonetheless, the size of these coefficients should be interpreted with care, given that these estimates represent intention-to-treat effects and the actual participation rate among individuals in the sample is unknown.

The strong improvement of the relation with the teacher due to JeKi could actually reflect the parents' appreciation of the program rather than the attitude of the child itself. Given that the information is provided by parents, they might judge their child's relation with the teacher better, because they appreciate the existence of the JeKi program at school. At the same time, one could argue that parents who answer questions about their child's relation with the teacher primarily focus on the main teacher, given that she or he spends much more time with the children at school than the JeKi teacher, who visits from the local music school once or twice per week.

The effects of low music school fees on non-cognitive skills are not presented here. The main reason is that the treatment is not very well defined. Even if low music school fees lead children to sign up at a local music school, it is not obvious which treatment they receive. Music schools propose a diverse course offer, ranging from basic introductory classes presenting various musical instrument, to instrument lessons for individuals or small groups to ensemble lessons such as orchestra or harmony. On average, only $62 \%$ of the students attending public music schools receive traditional musical instrument lessons (see Table A.10). While any of these courses might affect non-cognitive skills, they do so through multiple channels. Results would therefore be difficult to interpret or to compare to the effects of the JeKi program, where the treatment is similar across participants. Nonetheless, the effects of low music school fees on non-cognitive skills were estimated and did not yield any interesting or significant results (Table B.17).

The effects of JeKi on socio-emotional skills are larger for boys and among children from richer households (columns 2 to 5). The former seem to considerably improve their appreciation of school and studying as a consequence of the JeKi program, both to a large extent of more than half of a standard deviation. The attitude toward school is also affected among 
children from households with an above-median income. The strong overall positive effect on conduct, by contrast, is mainly driven by girls and children from richer households. Potentially due to the small sample size, the pattern of heterogeneities is rather unstable when socioeconomic background is defined using parental education or the child's migration background (see Table B.18). When differentiating by parental education, it seems that the improvements in conduct and relations with the teacher are rather driven by children with less highly educated parents.

Anderson (2008) points out that studies examining multiple hypotheses typically find some positive effects simply due to false rejections of the null hypothesis. He stresses this as an issue that does not receive sufficient attention in economic research. Given that the sample size is rather small in the present study and that effect sizes seem to vary a lot, random rejections of the null hypothesis might explain some or all of the significant coefficients discussed above.

A simple way to reduce the number of hypotheses tested is to aggregate outcomes into a joint index (Anderson, 2008). The bottom part of Table 4 shows the effect of the JeKi program on two such aggregated outcome indices. The first is a weighted average of all ten non-cognitive outcomes presented in the upper part of the table. In the aggregation, each normalized outcome is weighted by the inverse of its covariance matrix with respect to all other non-cognitive outcomes. With other words, outcomes receive more weight in the aggregated index to the extent that they add new information to the index (Anderson, 2008). The second simply takes the average of the four difficulties from the Strengths and Difficulties Questionnaire: emotional symptoms, conduct problems, hyperactivity and peer problems. The coefficients of both aggregate outcomes are similar in size, but only statistically significant in the index, which summarizes all non-cognitive skills. The previous finding is confirmed, according to which effects are larger for boys and children from richer households.

\subsection{Graphical evidence on the effects on music and socio-emotional skills}

Figure 3 graphically illustrates some of the results for the JeKi treatment. The graph shows mean values of the outcomes for each cohort of students. The x-axis indicates the year of school enrollment. For each outcome, the black line represents the cohorts of children living in JeKi areas, both before and after the program was implemented. The dotted gray lines provide the mean outcome values for children in areas where JeKi never existed. Most of the JeKi programs were created in 2007 or 2008, as illustrated by the gray bar, but some were implemented as late as 2011. All averages are unconditional, without taking control variables into account.

The graphs confirm the regression results from Table 4. Before JeKi was created, music activities were lower in treatment than control regions. With the start of the first programs in 2007/2008, JeKi areas showed an increase in childhood music activities, while participation in other areas remained constant. The graphs also show that, with respect to socio-emotional skills, children in JeKi areas were generally doing less well before the program was implemented. Their appreciation of school and studying were approximately one fifth of a standard deviation lower, they had more conduct problems and got along less well with their teacher. When more and more children in these areas received the opportunity to take part in the JeKi program, these gaps gradually closed or even reversed. 
Figure 3 - Unconditional effects of the JeKi program
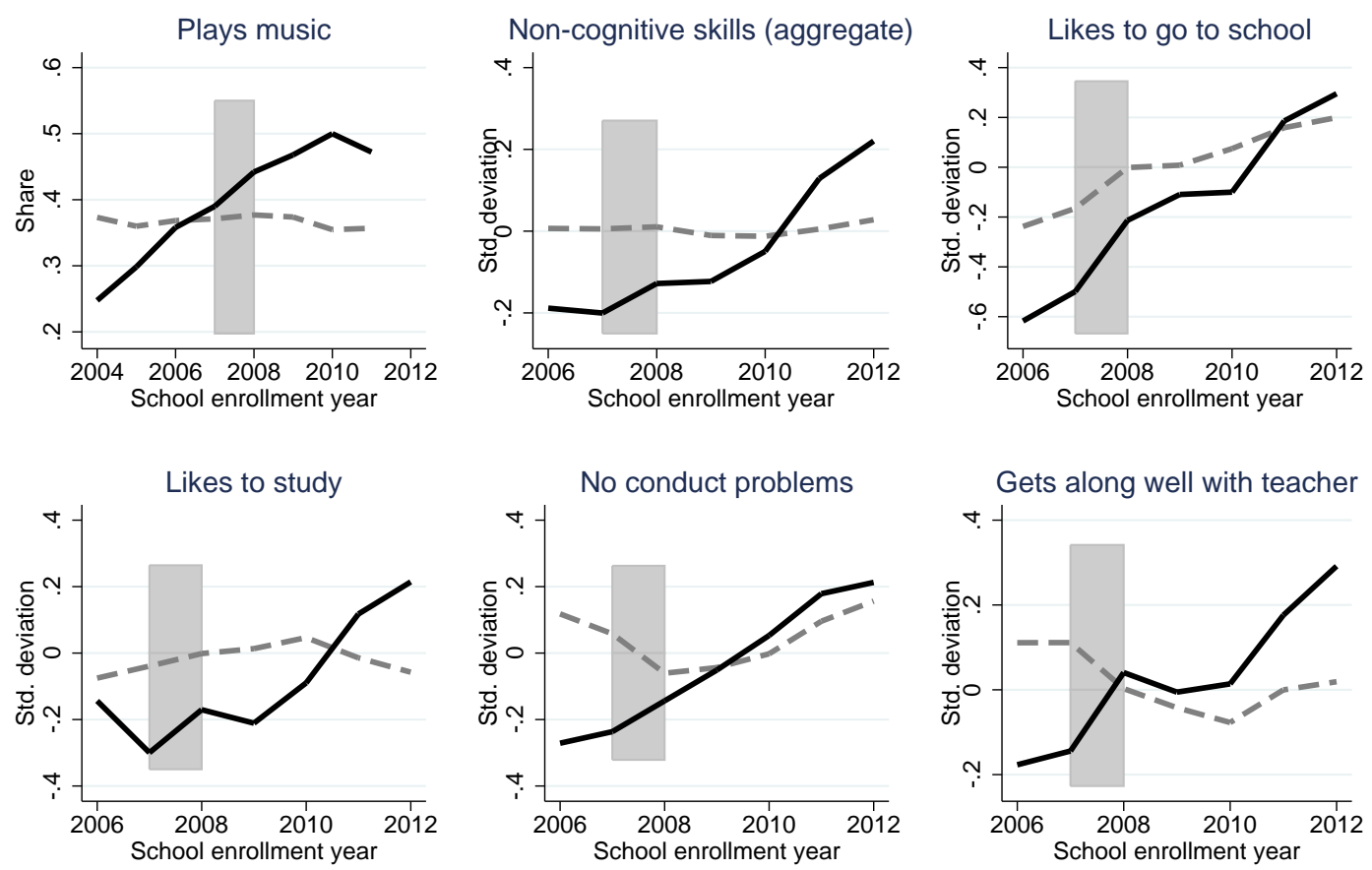

- $-=-$ Control group (moving average)

Treatment group (moving average)

Source: SOEP v30 and FiD v4, own calculations. The black line shows yearly averages of outcome variables for students living in JeKi regions (both before and after the implementation of the program). The dotted gray line shows these averages for children in non-JeKi regions. All averages are moving averages of a 3-year window. The gray bar illustrates the years in which most of the JeKi projects were introduced.

Difference-in-differences estimators identify causal effects under the assumption of a common trend. With other words, in absence of treatment, outcomes in areas with and without JeKi are assumed to evolve similarly. Unfortunately, "playing music" is the only outcome variable for which we have several years of data before the first JeKi project was implemented. Figure 3 shows that the positive trend in music activities in treatment areas already existed prior to the implementation of JeKi. One explanation could be that some schools propose similar activities in advance, knowing that JeKi would be offered in the following year. The graph depicts 3-year moving averages, which could partly explain the pre-treatment positive trend as well.

To further investigate the plausibility of the common trend assumption, I plotted the same graph once again (Figure 4), this time describing the evolution of some control variables for the treatment and control group. These indicators of socio-economic status should not be affected by the existence of JeKi schools and thereby serve as a test for the common trend assumption.

The graph illustrates that some of the covariates indeed move in parallel between treatment and control group. These are - among many others not drawn in the graph - the year of school enrollment, whether the child lives in a single parent home, and whether she or he has a migration background. The lower part of Figure 4, however, shows that some covariates clearly do not move similarly in both groups. These are very relevant variables, which have been shown to 
Figure 4 - Evolution of covariates in treatment and control group
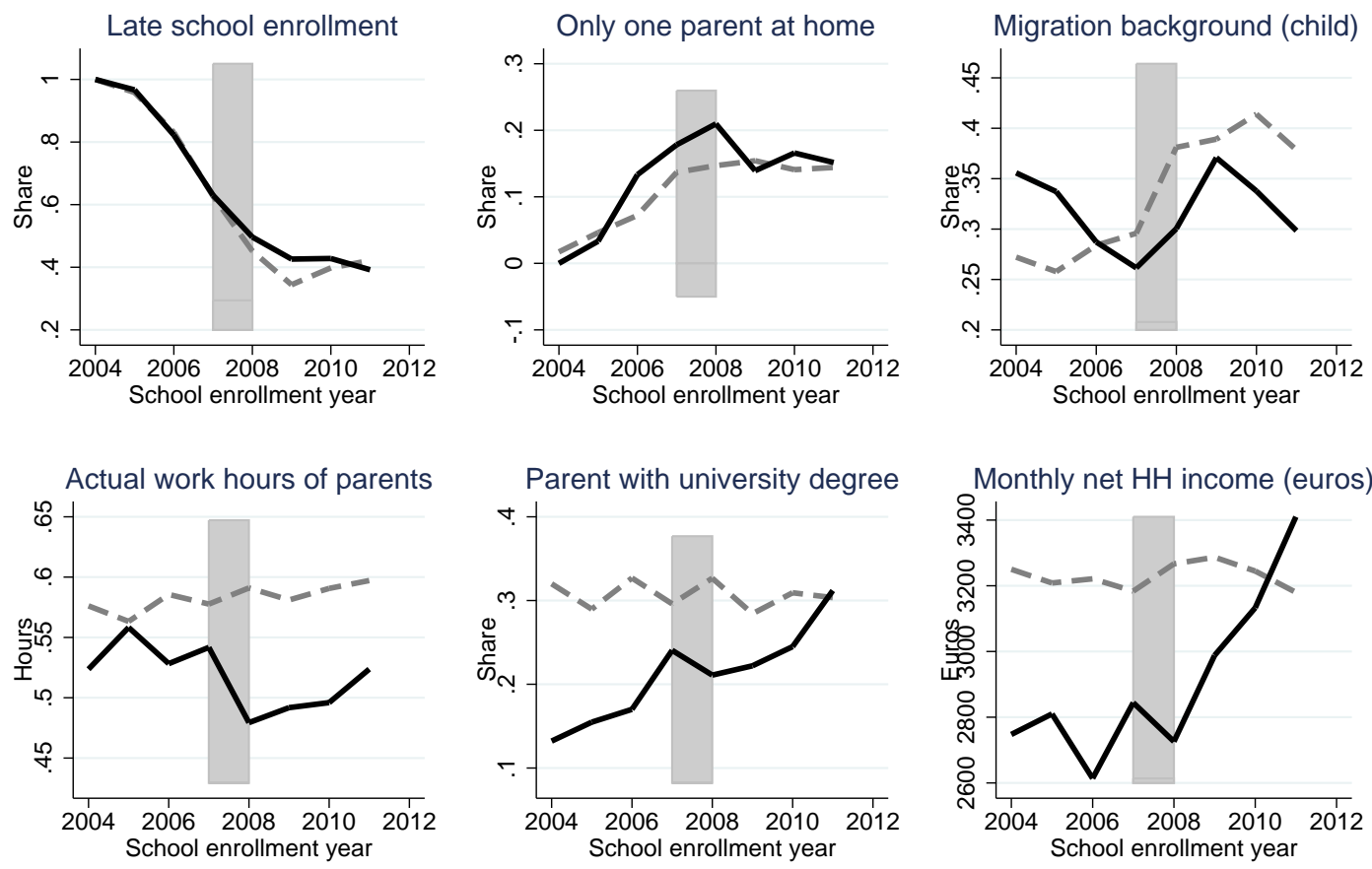

- Control group (moving average)

Treatment group (moving average)

Source: SOEP v30 and FiD v4, own calculations. The graph shows yearly averages of some of the control variables used in this study, separately for students living in JeKi regions (black line, both before and after the implementation of the program) and for children in non-JeKi regions (dotted line). All averages are moving averages of a 3-year window. The gray bar illustrates the years in which most of the JeKi projects were introduced.

affect participation in non-formal activities and skill development: the mother's education and work hours, as well as household income. These variables are taken into account in the main estimations of this paper, however, further unobserved characteristics might also not follow a parallel trend between treatment and control group. This is problematic, at least to the extent that these variables are uncorrelated with the control variables included in this study.

\subsection{Comparing JeKi to varying local public music school fee levels}

As described in Section 3, the effects of the JeKi program partly depend on activities that would have been carried out in absence of the program. Whether JeKi provides an advantageous opportunity to learn a musical instrument depends, among others, on the cost of taking music lessons outside the program. To explicitly model this trade-off, Table 5 shows the effects of JeKi separately in comparison to having access to music schools charging below or above average fees. A third comparison in the table examines the effects of below-average compared to above-average music school fees in regions that are not covered by the JeKi program.

The estimations presented so far give no hint as to whether the effects of the JeKi program can be attributed to learning to play a musical instrument or whether they result from other program characteristics, such as playing in a group or spending more time at school. If the for- 
Table 5 - Effect of a combined treatment (OLS estimates)

\begin{tabular}{|c|c|c|c|c|c|c|}
\hline \multirow[t]{2}{*}{$\begin{array}{ll}\text { Treatment } & \Longrightarrow \\
\text { Control } & \Longrightarrow\end{array}$} & \multicolumn{2}{|c|}{$\begin{array}{c}\text { Comparison 1: } \\
\text { JeKi } \\
\text { Low music school fees }\end{array}$} & \multicolumn{2}{|c|}{$\begin{array}{c}\text { Comparison 2: } \\
\text { JeKi } \\
\text { High music school fees }\end{array}$} & \multicolumn{2}{|c|}{$\begin{array}{c}\text { Comparison 3: } \\
\text { Low music school fees } \\
\text { High music school fees }\end{array}$} \\
\hline & Diff. & $p$-value & Diff. & p-value & Diff. & p-value \\
\hline \multicolumn{7}{|l|}{ MUSIC ACTIVITIES } \\
\hline Plays music & 0.08 & 44 & 0.22 & 1 & 0.08 & 12 \\
\hline Sample size & 347 & & 779 & & 868 & \\
\hline \multicolumn{7}{|l|}{ NON-COGNITIVE SKILLS } \\
\hline \multicolumn{7}{|c|}{ Strengths and Difficulties Questionnaire } \\
\hline No emotional symptoms & -0.16 & 59 & -0.09 & 69 & -0.19 & 15 \\
\hline No conduct problems & 0.10 & 71 & 0.72 & 1 & -0.20 & 10 \\
\hline Not hyperactive & 0.03 & 93 & 0.19 & 38 & 0.07 & 44 \\
\hline No peer problems & -0.03 & 92 & -0.05 & 83 & -0.12 & 32 \\
\hline Pro-social behavior & -0.09 & 76 & 0.23 & 45 & 0.11 & 45 \\
\hline \multicolumn{7}{|l|}{ Attitude towards school } \\
\hline Likes to go to school & 0.13 & 55 & 0.34 & 27 & 0.17 & 21 \\
\hline Likes to study & 0.45 & 13 & 0.08 & 76 & 0.07 & 60 \\
\hline Follows lessons well & 0.18 & 48 & -0.18 & 67 & 0.16 & 9 \\
\hline Gets along well... & & & & & & \\
\hline ...with classmates & 0.24 & 31 & -0.02 & 93 & 0.03 & 79 \\
\hline ...with teacher & 0.33 & 5 & 0.26 & 11 & -0.09 & 59 \\
\hline \multicolumn{7}{|c|}{ Combined non-cognitive skills scores } \\
\hline Non-cog. skills (aggregate) & 0.11 & 31 & 0.15 & 27 & 0.01 & 93 \\
\hline Difficulties (from SDQ) & -0.02 & 96 & 0.30 & 8 & -0.15 & 19 \\
\hline Sample size & 243 & & 540 & & 595 & \\
\hline
\end{tabular}

Source: SOEP v30 and FiD v4, own calculations. Each cell is a separate OLS regression. Three columns present pairwise comparisons of three possible states of a treatment variable, which takes on the following values (the three groups are mutually exclusive): (1) Among the five closest primary schools, the share of students in a school having the JeKi program in the year of school enrollment is larger than $50 \%$ (same definition as in Table 4); (2) No JeKi program, but fees at the closest public music school are below the 33rd percentile; (3) No JeKi program and fees at the closest public music school are above the 33rd percentile. Please refer to Section 4 for more details on the treatment definition. All regressions control for individual and regional characteristics, as well as time and county fixed effects. Standard errors are clustered at the county level. The number of observations, as well as the R-squares for each regression can be provided on request. "Plays music" is a binary variable indicating whether the child played a musical instrument at or outside school at age 9. All other outcome variables are normalized with mean 0 and a standard deviation of 1 within the control group. The exact definitions of all outcome and control variables are given in Table A.7.

mer is true, we would expect the effects to be smaller when comparing JeKi to areas with low rather than high public music school fees. Children in non-JeKi areas with low music school fees are more likely to play music as well than those who have to pay a lot for musical instrument lessons. If JeKi has smaller effects in comparison to areas with low music school fees (where children are more likely to play music), the estimated effects are at least partly due to the activity of playing music. By contrast, if the effects are similar, no matter whether JeKi is compared to areas with high or low music school fees, these effects are likely to result from other program characteristics.

The results in the first row of Table 5 perfectly illustrate the cost differences for taking music lessons according to the level of music school fees. JeKi increases the probability to play a mu- 
sical instrument by an insignificant 8 percentage points in areas with music school fees in the lowest third of the fee distribution. In areas, where music schools are more expensive and therefore the opportunity created by JeKi potentially matters more, musical activities increase by 22 percentage points thanks to the existence of the program. The comparison between non-JeKi regions with high and low music school fees reveals the expected pattern with music participation being 8 percentage points higher in regions with cheaper music schools. However, this difference is not statistically significant.

The lower part of Table 5 reveals that the positive effect of JeKi on conduct discussed above is driven by the comparison with areas where music schools charge high fees. Moreover, in this comparison, JeKi reduces children's general level of difficulties by almost a third of a standard deviation. By contrast, the improved relation with the teacher, which is caused by JeKi, is somewhat stronger in comparison to regions with low music school fees. An interpretation, which is in line with the hypotheses discussed in section 3, would be that playing music improves children's behavior, while small group activities positively affect relations with teachers. However, given the small sample size, we should be careful with such conclusions, as these positive and significant coefficients might appear by chance. Moreover, the aggregated non-cognitive skills score does not show significant coefficients in any of the three comparisons from Table 5.

\subsection{Robustness}

To examine the robustness of the results presented above, I performed various tests assessing the sensitivity of the main estimates with respect to measurement error, estimation procedures as well as the identifying assumptions. All tables showing these tests are presented in Appendix B.3.

As the construction of both treatment variables involved various steps (see Section 4), I extensively test whether the results change for alternative treatment definitions. For each treatment (JeKi and below-average music school fees), I test six alternative definitions and find that they all yield qualitatively similar results (Tables B.19 and B.20).

As described in Section 4, all outcome variables were measured at age 8 and 10. To increase the sample size, the main specification measures the outcomes at age 10 if available, and pools these with the additional observations for which outcomes are only available at age 8. Outcomes are only available at age 8 for one third of the sample. For another third, outcomes are only available at age 10. A third of the sample therefore reported all outcomes both at age 8 and 10. In a robustness check, I estimated the treatment effects separately for all individuals at age 8 and at age 10 (Table B.21). All effects are rather similar for both ages, which might seem surprising given that 8-year-old JeKi participants only attended the program for one or two years. An explanation could be that JeKi is mandatory in the first, but voluntary in the second year and thereafter. The share of individuals in the sample who actually take part in the program is higher at age 8 than age 10. Given that I estimate intention-to-treat effects, which average over the effects for participants and non-participants, longer participation (and thereby potentially larger effects) might cancel out with a lower number of participants.

The outcome variable describing music activities is composed of the answers to two questionnaire items, referring to music activities at or outside school. To test the robustness of 
the results with respect to the decision to pool these two questionnaire items, I separately examined the results for music activities at and outside school (Table B.22). Besides being less precisely estimated, the JeKi program has a much stronger effect on within-school activities when measured at age 8 , while at age 10 some parents might consider the program to be an out-of-school activity. That seems plausible, given that in the first year, the program is carried out by the regular school teacher, while subsequent years are taught by teachers from a local music school.

In addition to examining the robustness of the results with respect to variable definitions, I re-estimated the effects using different estimation methods and samples. First, I re-estimated all effects using propensity score matching and entropy balancing rather than OLS (Table B.23, columns 1 and 2). The results are very similar. Second, I excluded all observations with at least one missing value on any of the covariates, which reduces the sample size by about $12 \%$ (Table B.23, column 3). This also does not change the results. In any case, the treatment has no relevant effects on whether a covariate is missing (Table B.22). Next, I estimated the effects without using a difference-in-differences estimator, which leaves them similar, and without including any covariates, which slightly increases them (Table B.24, columns 2 and 3). The results remain also similar when including panel weights, which are designed to make the data representative of the German population (Table B.24, column 1). As one (surprising) exception, including these survey weights eliminates the effect of JeKi on music activities.

Finally and most importantly, I assess the sensitivity of the results with respect to the identifying assumptions. The results of this paper have a causal interpretation if the following two statements are valid. First, in absence of the program, outcomes would have evolved similarly in regions (or schools) with and without regions (the common trend assumption). Second, families do not move to JeKi areas, in order to be able to benefit from the program.

In addition to the graphical evidence presented in Figure 3, I assess the plausibility of the common trend assumption by evaluating a placebo treatment. For the placebo treatment, I assume that each JeKi project started one year earlier than it actually did. Effects are estimated for the placebo start year, controlling for the actual JeKi start. If the placebo treatment shows positive effects, it is likely that JeKi schools already evolved differently even before the program was implemented. For the music school fee treatment, low music schools are drawn randomly. The results show that the common trend assumption might be violated with respect to the child's relations with the teacher, which also strongly improve thanks to the placebo treatment, even though the coefficients are not significant (Table B.25, column 1).

A second test of the common trend assumption examines how the JeKi program affects pretreatment outcomes. According to Imbens and Wooldridge (2009), such tests using placebo outcomes are the more powerful, the more the placebo outcomes are closely related to the outcomes of interest. For this test, I benefit from the fact that some of the outcomes (music activities and the Strengths and Difficulties Questionnaire) were also measured when children were 6 years old. As JeKi only starts in the first grade of primary school, which children enter at age 6 or 7, these outcomes should not be affected by the program. Indeed, while some of the coefficients are large in magnitude, they are negative rather than positive, and (mostly) not statistically significant (Table B.25, column 2). Low music school fees also have an effect on 
music activities at age 6 , because these almost do not vary over time and thus children were also treated at that age.

A third test is related to the assumption that families do not move to live closer to a JeKi school. To test this, I carried out three additional estimations (Table B.26). First, I assumed that children only attend schools within their municipality. Second and third, I restricted the estimation sample to those for whom I know that they did not move between entering the data/age 5 and when the outcomes are measured (age 8 or 10). As the decision about a new school entering the JeKi program was solely taken in the previous school year, I assume that parents could not have known about the program two years before their child entered primary school. The results are very similar to the main estimation results, which are therefore not driven by those who move. We should note, however, that this test has limited power, given that the subsample of non-movers is likely to be selective as well. It is therefore not obvious who is compared to whom in this test.

\section{Conclusion}

This paper examines if the universal music education program JeKi Uedem Kind ein Instrument, an instrument for every child) affects its stated goal of providing access to musical instrument lessons to children from disadvantaged social backgrounds. I find that the program increases music participation among children from families with a household income below the median by 30 percentage points. Given that only $25 \%$ of these children played a musical instrument previously, this amounts to an increase of $115 \%$. Despite being voluntary after the first year, the program thus successfully reaches those who did not attend musical instrument lessons before. The study by Busch and Kranefeld (2013) also finds that the choice to pursue the JeKi program beyond the mandatory first year depends neither on socio-economic status nor migration background.

However, JeKi does not affect music participation among children from households with an income above the median. This might be due to the fact that I use data measuring the incidence rather than the amount of music activities. Children from richer households are likely to learn a musical instrument, irrespective of whether they receive specific incentives at school. Given the data used, I am unable to identify whether participation in the JeKi program comes in addition to or instead of regular music school classes.

JeKi increases music participation more effectively than the alternative policy of low public music school fees. If the music school closest to a child's home charges fees within the lowest third of federal state's music school fee distribution, children from low-income households increase music participation as well. At 16 percentage points, this effect is lower than that of the JeKi program. Public music schools in Germany are obliged to charge lower fees from lowincome households. The average fee level measured in the data might therefore not apply to the poorest households, which could partly explain the lower effect size.

Furthermore, this paper investigates whether JeKi affects the development of social and emotional skills. I find that the program improves conduct problems and relations with the teacher by about one half of a standard deviation. However, these effect sizes should be interpreted with care, given that they estimate intention-to-treat effects and the exact share of 
participating students is unknown. Effects are larger among boys and children from families with a household income above the median, who also like school and studying more thanks to the program.

Thorough robustness checks verify the sensitivity of these results with respect to multiple hypothesis testing, measurement error and the identifying assumptions. JeKi improves an aggregate index of socio-emotional skills by one sixth of a standard deviation. This confirms that the above-mentioned effects are not solely due to random and false rejections of the null hypothesis. All results are also robust to defining treatments, outcomes and socio-economic status differently, measuring outcomes at various ages, changing the estimation method, including survey weights, as well as restricting the sample to children with non-missing covariates.

The findings of this paper can be interpreted as causal, if areas with and without the JeKi program would have evolved similarly in absence of the JeKi program and if families did not move in order to live closer to a JeKi school. Given the large number of individual and regional control variables included in all estimations, as well as the broad availability of voluntary extracurricular music activities in all regions of Germany, these assumptions seem plausible. Moreover, outcomes are not affected by a placebo treatment happening one year earlier, and the JeKi program does not affect pre-treatment outcomes. In addition, results remain identical within the subsample of children who did not move between age 6 and 10 .

To discuss the enormous expectations of policymakers, according to which universal music education is essential for children's personality development, we should ask whether the abovementioned positive effects are a result of playing music. The JeKi program involves learning a musical instrument by interacting with teachers in small groups, and additionally joining an orchestra in grades 3 and 4 . This study is unable to identify mechanisms that distinguish between these components. However, improvements in social skills and student-teacher relations are likely to result from the group-related component of the JeKi program. Nonte and Schwippert (2014) are unable to find positive effects of JeKi when comparing it to schools with an intensified sports curriculum. Hence, a program proposing sports or theater lessons in small groups might result in similar outcomes. Moreover, critics of the JeKi program state that it does not match regular music school courses with respect to quality, because classes are large and participation not entirely voluntary (Bossen, 2009). This could be another reason for a lack of music-specific effects like those found by Hille and Schupp (2015).

The primary goal of JeKi - to give children from less favorable socio-economic backgrounds access to music education - appears to be fulfilled. However, additional research is needed to find conclusive evidence on whether these programs affect cognitive and non-cognitive skills, as well as other educational outcomes. Further studies should use more detailed data and distinguish the mechanisms at work by comparing similar policies that differ in terms of content and implementation. A cost-benefit or cost-effectiveness analysis comparing different policies could determine to what extent such potential additional skill-related effects provide a further justification for public policy intervention. 


\section{Acknowledgments}

This research is funded by the German Research Foundation (DFG) in the context of the Collaborative Research Center 882 "From Heterogeneities to Inequalities" (Project A1 Social Closure and Hierarchization). I thank C. Katharina Spieß, Jürgen Schupp, Stefan Bauernschuster, Brian McCall, Ludger Wößmann, Stefan C. Wolter, as well as seminar participants at DIW Berlin and the University of Bielefeld, as well as conference participants at the Young Economists Meeting Brno and the 6th International Workshop on the Applied Economics of Education for their comments. Special thanks to Adam Lederer for his support with English language editing. The author is responsible for all errors.

\section{References}

Almlund, M., Duckworth, A. L., Heckman, J. J., Kautz, T., 2011. Personality psychology and economics. In: Hanushek, E. A., Machin, S., Woessmann, L. (Eds.), Handbook of the Economics of Education. Vol. 4. Elsevier Amsterdam, pp. 1-181.

Anderson, M. L., 2008. Multiple inference and gender differences in the effects of early intervention: A reevaluation of the Abecedarian, Perry Preschool, and Early Training Projects. Journal of the American Statistical Association 103 (484), 1481-1495.

Barnett, W. S., 2011. Effectiveness of early educational intervention. Science 333 (6045), 975-978.

Bauernschuster, S., Falck, O., Woessmann, L., 2014. Surfing alone? The internet and social capital: Evidence from an unforeseeable technological mistake. Journal of Public Economics 117, 73 - 89.

BBSR, 2015. Indikatoren und Karten zur Raum- und Stadtentwicklung (INKAR). Federal Institute for Research on Building, Urban Affairs and Spatial Development (BBSR), www.inkar.de (accessed April 27th, 2015).

BDPM, 2015. Über uns. Bundesverband deutscher Privatmusikschulen, http://www.bdpmmusikschulverband.de/aufgaben/ueber-uns/ (accessed April 22nd, 2015).

Bertrand, M., Pan, J., 2013. The trouble with boys: Social influences and the gender gap in disruptive behavior. American Economic Journal: Applied Economics 5 (1), 32-64.

BMAS, 2015. The educational package: A new start for taking part. Brochure by the Federal Ministry of Labour and Social Affairs.

Bossen, A., 2009. Jeki: Die Zweifel sind übermächtig. Neue Musikzeitung 58 (10).

BSB, 2009. Jedem Kind ein Instrument: Auftaktveranstaltung in der Fridjof-Nansen-Schule mit Senatorin Christa Goetsch. Pressemitteilung 18. Sep 2009, Behörde für Schule und Berufsbildung, http://bildungsserver.hamburg.de/contentblob/3873800/data/download-pdf-18-09-2009-pressemitteilungzur-veranstaltung-mit-senatorin-goetsch-zum-jeki-start.pdf (accessed January 30th, 2015).

Busch, T., Kranefeld, U., 2013. Wer nimmt an JeKi teil und warum? Programmteilnahme und musikalische Selbstkonzepte. In: Koordinierungsstelle (Ed.), Broschüre: JeKi-Forschungsschwerpunkt. Bielefeld, pp. 46 - 49.

Cabane, C., Hille, A., Lechner, M., 2015. Mozart or Pelé? The effects of teenagers' participation in music and sports. Economics working paper series 1509, University of St. Gallen, School of Economics and Political Science.

Cabane, C., Lechner, M., 2015. Physical activity of adults: A survey of correlates, determinants, and effects. Jahrbücher für Nationalökonomie und Statistik 235 (4-5), 367-402.

Carneiro, P., Crawford, C., Goodman, A., 2007. The impact of early cognitive and non-cognitive skills on later outcomes. CEE Discussion Paper 92, Centre for the Economics of Education, LSE.

Castillo, M., Ferraro, P. J., Jordan, J. L., Petrie, R., 2011. The today and tomorrow of kids: Time preferences and educational outcomes of children. Journal of Public Economics 95 (11-12), 1377-1385.

CDU, 2013. Deutschlands Zukunft gestalten: Koalitionsvertrag zwischen CDU, CSU und SPD. https://www.cdu.de/sites/default/files/media/dokumente/koalitionsvertrag.pdf, accessed March 12th, 2015.

Covay, E., Carbonaro, W., 2010. After the bell: Participation in extracurricular activities, classroom behavior, and academic achievement. Sociology of Education 83 (1), 20-45. 
Creech, A., Gonzalez-Moreno, P., Lorenzino, L., Waitman, G. (Eds.), 2013. El Sistema and Sistema-inspired programmes: A literature review of research, evaluation, and critical debates. Sistema Global.

Cunha, F., Heckman, J. J., 2007. The technology of skill formation. American Economic Review 97 (2), 31-47.

Cunha, F., Heckman, J. J., Schennach, S. M., 2010. Estimating the technology of cognitive and noncognitive skill formation. Econometrica 78 (3), 883-931.

Currie, J., 2001. Early childhood education programs. The Journal of Economic Perspectives 15 (2), $213-238$.

Dahmann, S., Anger, S., 2014. The impact of education on personality: Evidence from a German high school reform. IZA Discussion Papers 8139, Institute for the Study of Labor (IZA).

Deutscher Städtetag (Ed.), 2009. Statistisches Jahrbuch deutscher Gemeinden.

Deutscher Städtetag (Ed.), 2013. Statistisches Jahrbuch deutscher Gemeinden.

Falck, O., Mang, C., Woessmann, L., 2015. Virtually no effect? Different types of computer use and the effect of classroom computers on student achievement. Working paper, Ifo Institute at the University of Munich.

Goebel, J., Pauer, B., 2014. Datenschutzkonzept zur Nutzung von SOEPgeo im Forschungsdatenzentrum SOEP am DIW Berlin. Zeitschrift für amtliche Statistik Berlin Brandenburg 3, 42-47.

Goodman, R., 1997. The Strengths and Difficulties Questionnaire: A research note. Journal of Child Psychology and Psychiatry 38 (5), 581-586.

Grgic, M., Züchner, I. (Eds.), 2013. Medien, Kultur und Sport. Was Kinder und Jugendliche machen und ihnen wichtig ist. Die MediKuS-Studie. Beltz Juventa.

Hainmueller, J., 2012. Entropy balancing for causal effects: A multivariate reweighting method to produce balanced samples in observational studies. Political Analysis 20 (1), 25-46.

Hainmueller, J., Xu, Y., 2013. ebalance: A stata package for entropy balancing. Journal of Statistical Software 54 (7).

Heckman, J., Pinto, R., Savelyev, P., 2013. Understanding the mechanisms through which an influential early childhood program boosted adult outcomes. American Economic Review 103 (6), 2052-86.

Heckman, J. J., Kautz, T., 2012. Hard evidence on soft skills. Labour Economics 19, 451-464.

Heckman, J. J., Kautz, T., 2014. The Myth of Achievement Tests: The GED and the Role of Character in American Life. Chicago, IL: University of Chicago Press, Ch. Fostering and Measuring Skills: Interventions that Improve Character and Cognition, pp. 293-317.

Heineck, G., Anger, S., 2010. The returns to cognitive abilities and personality traits in Germany. Labour Economics 17 (3), 535-46.

Hille, A., 2010. Etude d'impact des Orchestres à l'Ecole. Institut Montaigne.

Hille, A., Arnold, A., Schupp, J., 2014. Leisure behavior of young people: Education-oriented activities becoming increasingly prevalent. DIW Economic Bulletin 4 (1), 26-36.

Hille, A., Schupp, J., 2015. How learning a musical instrument affects the development of skills. Economics of Education Review 44, 56-82.

Huber, M., Lechner, M., Steinmayr, A., 2015. Radius matching on the propensity score with bias adjustment: Finite sample behaviour, tuning parameters and software implementation. Empirical Economics 49 (1), 1-31.

Imbens, G. W., 2015. Matching methods in practice: Three examples. Journal of Human Resources 50 (2), $373-419$.

Imbens, G. W., Wooldridge, J. M., 2009. Recent developments in the econometrics of program evaluation. Journal of Economic Literature 47 (1), 5-86.

IT.NRW, 2011. Verzeichnis der allgemeinbildenden Schulen in Nordrhein-Westfalen 2011. Information und Technik Nordrhein-Westfalen, Geschäftsbereich Statistik.

JeKi-Stiftung, 2008. “Jedem Kind ein Instrument" startet mit Erfolgsquote ins zweite Schuljahr. Pressemitteilung 28. Mai 2008, JeKi-Stiftung, https://www.jedemkind.de/programm/presse/eingebundene_dokumente/ 080528_pi_zwischenbilanz.pdf (accessed January 27th, 2015).

JeKi-Stiftung, 2011. Jedem Kind ein Instrument: Programmstandards. http://www.jekits.de/app/uploads/2014/10/120326_Programmstandards_2011_2012.pdf (accessed April 28th, 2015).

JeKi-Stiftung, 2013. Jedem Kind ein Instrument: Zahlen und Fakten. http://www.mfkjks.nrw.de/web/ media_get.php?mediaid=29707 \&fileid=98596 \&sprachid=1 (accessed April 28th, 2015).

JeKi-Stiftung, 2014. Jedem Kind ein Instrument: Programmbeschreibung. http://www.mfkjks.nrw.de/web/media_get.php?mediaid=29706\&fileid=98595\&sprachid=1 (accessed April 
28th, 2015).

JeKi-Stiftung, 2015. Informationen für Musikschulen. https://www.jedemkind.de/programm/ musikschulen/informationen.php (accessed January 27th, 2015).

Kulturstiftung, 2015. Jedem Kind ein Instrument: Programm zur Förderung der kulturellen Bildung - der Beitrag der Kulturstiftung des Bundes zur europäischen Kulturhauptstadt 2010. Kulturstiftung des Bundes, http://www.kulturstiftung-desbundes.de/cms/de/programme/kunst_der_vermittlung/archiv/jedem_kind_ein_instrument_2929_162.html (accessed July 24th, 2015).

Lareau, A., 2011. Unequal Childhoods: Class, Race, and Family Life, 2nd Edition. University of California Press.

Lechner, M., 2001. Identification and estimation of causal effects of multiple treatments under the conditional independence assumption. In: Lechner, M., Pfeiffer, F. (Eds.), Econometric Evaluation of Labour Market Policies. Vol. 13 of ZEW Economic Studies. Physica-Verlag HD, pp. 43-58.

Makles, A., Schneider, K., 2015. Much ado about nothing? The role of primary school catchment areas for ethnic school segregation: Evidence from a policy reform. German Economic Review 16 (2), 203-225.

MIZ, 2014. Kooperationen von Musikschulen im VdM mit allgemein bildenden Schulen und anderen Partnern. Deutsches Musikinformationszentrum (MIZ), http://www.miz.org/intern/uploads/statistik127.pdf (accessed April 22nd, 2015).

Nonte, S., Schwippert, K., 2014. Transfereffekte von Instrumentalunterricht. Der Einfluss des Instrumentalunterrichts auf die soziale und motivationale Entwicklung von Schülerinnen und Schülern im schulischen Kontext. In: Lehmann-Wermser, A., Busch, V., Schwippert, K., Nonte, S. (Eds.), Mit Mikrofon und Fragebogen in die Grundschule. Waxmann, Münster, pp. 31-62.

Ones, D. S., Dilchert, S., Viswesvaran, C., Judge, T. A., 2007. In support of personality assessment in organizational settings. Personnel Psychology 60 (4), 995-1027.

Richter, D., Metzing, M., Weinhardt, M., Schupp, J., 2013. SOEP scales manual. SOEP Survey Papers 138.

Riedel, A., Schneider, K., Schuchart, C., Weishaupt, H., 2010. School choice in German primary schools: How binding are school districts? Journal for Educational Research Online / Journal für Bildungsforschung Online 2 (1), 94-120.

Roberts, B., Robins, R., Trzesniewski, K., Caspi, A., 2003. Personality trait development in adulthood. In: Mortimer, J., Shanahan, M. (Eds.), Handbook of the Life Course. Handbooks of Sociology and Social Research. Springer US, pp. 579-595.

Roden, I., Grube, D., Bongard, S., Kreutz, G., 2014. Does music training enhance working memory performance? findings from a quasi-experimental longitudinal study. Psychology of Music 42 (2), 284-298.

Roden, I., Kreutz, G., Bongard, S., 2012. Effects of a school-based instrumental music program on verbal and visual memory in primary school children: a longitudinal study. Frontiers in Psychology 3 (572).

Schellenberg, E. G., 2004. Music lessons enhance IQ. Psychological Science 15 (8), 511-514.

Schröder, M., Siegers, R., Spieß, C. K., 2013. “Familien in Deutschland” - FiD. Schmollers Jahrbuch 133 (4), 595606.

Segal, C., 2008. Classroom behavior. Journal of Human Resources 43 (4), 783-814.

Segal, C., 2013. Misbehavior, education, and labor market outcomes. Journal of the European Economic Association 11 (4), $743-779$.

Southgate, D. E., Roscigno, V. J., 2009. The impact of music on childhood and adolescent achievement. Social Science Quarterly 90 (1), 4-21.

Statistisches Bundesamt, 2015. Schulen und Klassen nach Schularten: Allgemeinbildende und berufliche Schulen. Statistisches Bundesamt, https://www.destatis.de/DE/ZahlenFakten/GesellschaftStaat/BildungForschungKultur/ Schulen/Tabellen/AllgemeinBildendeBeruflicheSchulenSchularten.html (accessed July 24th, 2015).

Todd, P. E., Wolpin, K. I., 2003. On the specification and estimation of the production function for cognitive achievement. The Economic Journal 113 (485), F3-F33.

VDM, 2011. Richtlinien für die Mitgliedschaft im Verband deutscher Musikschulen e.V. (VdM). Verband deutscher Musikschulen, http://www.musikschulen.de/medien/doks/vdm/richtlinien-des-vdm-2011_logo.pdf (accessed June 16th, 2014). 
VDM, 2014. Mitgliedschulen im VdM. Verband deutscher Musikschulen, http://www.musikschulen.de/ musikschulen/fakten/vdm-musikschulen/index.html (accessed April 2nd, 2015).

Wagner, G. G., Frick, J. R., Schupp, J., 2007. The German Socio-Economic Panel Study (SOEP): Scope, evolution and enhancements. Schmollers Jahrbuch: Journal of Applied Social Science Studies / Zeitschrift für Wirtschaftsund Sozialwissenschaften 127 (1), 139-169.

Winner, E., Goldstein, T., Vincent-Lancrin, S., 2013. Art for Art's Sake? OECD Publishing.

\section{Appendix A. Data}

\section{Appendix A.1. Construction of data set}

Table A.6 - Sample construction

\begin{tabular}{lc}
\hline Sample... & Remaining observations \\
\hline ...including all children observed at least once between age 8 and 10 & 11302 \\
(in SOEP/FiD, includes the entire Federal Republic of Germany) & \\
...with complete information on federal state & 11086 \\
...restricted to North Rhine-Westphalia & 2445 \\
\hline
\end{tabular}

Music activities Non-cognitive skills

\section{Outcomes}

...which received questions on the outcomes ${ }^{1}$

$1018 \quad 736$

...with complete information on all outcomes (no missing answers)

1018

\section{Treatments}

...with complete information on both treatments ${ }^{2}$

\section{Covariates}

...with complete information on individual covariates ${ }^{3}$

...with complete information on regional covariates

\section{Final sample}

97

689

Valid observations in both outcome groups 548 Valid observations in at least one of the two outcome groups

\footnotetext{
${ }^{1}$ To receive the questions on music activities, parents had to answer the SOEP or FiD household questionnaire in 2006, 2008, 2010, 2011, 2012 or 2013. To receive questions on the non-cognitive skills studied in this paper (SDQ and school attitude), parents had to answer the FiD mother-child questionnaire at age 8 (administered every year between 2010 and 2013) or the SOEP or FiD mother-child questionnaire at age 10 (administered every year between 2010 and 2013 for the FiD sample, and in 2012 and 2013 for the SOEP sample). In other years, the relevant questions were not part of the survey, the drop in observations compared to the previous line is therefore exogenous.

${ }^{2}$ The treatment status is not available for some individuals due to missing information on the number of students at some primary schools (needed to calculate the JeKi share), and the fee revenues at some music schools (needed to calculate the average fees).

${ }^{3}$ The only covariates with missing values were the parents' work hours ( $7 \%$ missing), the mother's age ( $2 \%$ missing) and the child's migration background ( $1 \%$ missing). To prevent a further reduction of the sample size, I replaced missing values by 0 for binary and by the sample mean for continuous variables and added missing indicators in all regressions for these variables.

${ }^{4}$ These covariates are only included in the estimations on below-average music school fees. $3 \%$ of the observations with missing values were replaced by the sample mean. A missing indicator was included in all regressions.
} 
Table A.7 - Detailed description of all variables

\begin{tabular}{|c|c|c|c|}
\hline Variable & Description & Type & Data source \\
\hline \multicolumn{4}{|l|}{ TREATMENT VARIABLES } \\
\hline \multicolumn{4}{|l|}{ Treatments for main results } \\
\hline $\mathrm{T} 1$ : Jeki share $>50 \%$ & Main treatment, see Table 2 & Binary & Primary schools \\
\hline T2: Music sc. fees in lowest third & Main treatment, see Table 2 & Binary & Music schools \\
\hline Combined treatment & $\begin{array}{l}\text { 1: } \mathrm{T} 1=1(\text { JeKi share }>50 \%) \\
\text { 2: } \mathrm{T} 1=0 \text { and } \mathrm{T} 2=1 \\
\text { (No JeKi, music school fees in lowest } \\
\text { third) } \\
\text { 3: } \mathrm{T} 1=0 \text { and } \mathrm{T} 2=0 \\
\text { (No JeKi, music school fees above lowest } \\
\text { third) }\end{array}$ & Categories & $\begin{array}{l}\text { Music schools } \\
\text { Primary schools }\end{array}$ \\
\hline \multicolumn{4}{|l|}{ Treatments for robustness checks } \\
\hline JeKi share $>5 \%$ & $\mathrm{~T} 1$, but cutoff at $5 \%$ & Binary & Primary schools \\
\hline JeKi share $>50 \%$ (no radius limit) & T1, but includes schools farther than $5 \mathrm{~km}$ & Binary & Primary schools \\
\hline JeKi share (continuous) & $\mathrm{T} 1$, but not transformed into binary & Continuous & Primary schools \\
\hline JeKi share (weighted by distance) & $\begin{array}{l}\text { T1, but not transformed into binary, each } \\
\text { school receives weight, which linearly de- } \\
\text { creases with distance to child's residence }\end{array}$ & Continuous & Primary schools \\
\hline JeKi at closest school & Yes/no in year of school enrollment & Binary & Primary schools \\
\hline JeKi at 1 of 5 closest schools & Yes/no in year of school enrollment & Binary & Primary schools \\
\hline Fees below median & $\mathrm{T} 2$, average replaced by median & Binary & Music schools \\
\hline Music school fees < average & $\mathrm{T} 2$, 33rd percentile replaced by average & Binary & Music schools \\
\hline Fees (in Euros) & $\begin{array}{l}\text { T2, without calculating 33rd percentile } \\
\text { and transforming into binary }\end{array}$ & Continuous & Music schools \\
\hline Fees (in Euros, alt. def.) & $\begin{array}{l}\text { Like previous, but alternative calculation } \\
\text { of fees: Fee revenues divided by number } \\
\text { of classes instead of number of students }\end{array}$ & Continuous & Music schools \\
\hline Fees in lowest third (alt. def.) & $\mathrm{T} 2$, with alternative calculation of fees & Binary & Music schools \\
\hline \multicolumn{4}{|l|}{ Placebo treatments } \\
\hline Jeki share > 50\% (placebo) & $\mathrm{T} 1$, but as if JeKi started 1 year earlier & Binary & Primary schools \\
\hline Fees in lowest third (placebo) & $\begin{array}{l}\text { Random draw of same number of music } \\
\text { schools as in } \mathrm{T} 2\end{array}$ & Binary & Music schools \\
\hline \multicolumn{4}{|l|}{ OUTCOME VARIABLES } \\
\hline \multicolumn{4}{|l|}{ Music activities } \\
\hline Plays music & $\begin{array}{l}\text { Yes, if "Attends music club at school" or } \\
\text { "Music or singing lessons outside school" }\end{array}$ & Binary & $\mathrm{SOEP} / \mathrm{FiD}^{1}$ \\
\hline Plays music at school & Yes, if "Attends music club at school" & Binary & $\mathrm{SOEP} / \mathrm{FiD}^{1}$ \\
\hline
\end{tabular}

Table A.7 to be continued. 
Table A.7 continued.

\begin{tabular}{|c|c|c|c|}
\hline Variable & Description & Type & Data source \\
\hline Plays music outside school & $\begin{array}{l}\text { Yes, if "Music or singing lessons outside } \\
\text { school" }\end{array}$ & Binary & $\mathrm{SOEP} / \mathrm{FiD}^{1}$ \\
\hline \multicolumn{4}{|c|}{ Strengths and Difficulties Questionnaire (SDQ) } \\
\hline & Average for following items: Child... & & \\
\hline No emotional symptoms & $\begin{array}{l}\text {...is often unhappy or dejected (Reversed) } \\
\text {...is nervous or clingy in new situations, } \\
\text { loses self-confidence easily }(R) \\
\text {...has many fears, becomes frightened } \\
\text { easily }(R)\end{array}$ & $\begin{array}{l}\text { 3-point } \\
\text { Likert scale } \\
\text { (normalized) }\end{array}$ & $\mathrm{SOEP} / \mathrm{FiD}^{2}$ \\
\hline No conduct problems & $\begin{array}{l}\text {...often has tantrums, has a temper }(R) \\
\text {...quarrels a lot with other children, picks } \\
\text { on them }(R)\end{array}$ & $\begin{array}{l}\text { 3-point } \\
\text { Likert scale } \\
\text { (normalized) }\end{array}$ & $\mathrm{SOEP} / \mathrm{FiD}^{2}$ \\
\hline Not hyperactive & $\begin{array}{l}\text {...is agitated, hyperactive, cannot sit still } \\
(R) \\
\text {...is fidgety }(R) \\
\text {...is easily distracted and lacks concentra- } \\
\text { tion }(R) \\
\text {...finishes tasks, is able to concentrate } \\
\text {...thinks before acting }\end{array}$ & $\begin{array}{l}\text { 3-point } \\
\text { Likert scale } \\
\text { (normalized) }\end{array}$ & $\mathrm{SOEP} / \mathrm{FiD}^{2}$ \\
\hline No peer problems & $\begin{array}{l}\text {...is a loner, usually plays by herself }(R) \\
\text {...is popular with other children } \\
\text {...is often made fun of or picked on by } \\
\text { other children }(R) \\
\text {...gets along better with adults than with } \\
\text { other children }(R)\end{array}$ & $\begin{array}{l}\text { 3-point } \\
\text { Likert scale } \\
\text { (normalized) }\end{array}$ & $\mathrm{SOEP} / \mathrm{FiD}^{2}$ \\
\hline Pro-social behavior & $\begin{array}{l}\text {...is considerate } \\
\text {...likes to share with others (sweets, toys, } \\
\text { crayons) } \\
\text {...is helpful if others are hurt, sick or sad } \\
\text {...helps others of his/her own accord } \\
\text { (parents, teachers, other children) }\end{array}$ & $\begin{array}{l}\text { 3-point } \\
\text { Likert scale } \\
\text { (normalized) }\end{array}$ & $\mathrm{SOEP} / \mathrm{FiD}^{2}$ \\
\hline \multicolumn{4}{|l|}{ Attitude toward school } \\
\hline Likes to go to school & "fully applies" to "does not apply" & $\begin{array}{l}\text { 4-point } \\
\text { Likert scale } \\
\text { (normalized) }\end{array}$ & $\mathrm{SOEP} / \mathrm{FiD}^{2}$ \\
\hline Likes to study & "fully applies" to "does not apply" & $\begin{array}{l}\text { 4-point } \\
\text { Likert scale } \\
\text { (normalized) }\end{array}$ & $\mathrm{SOEP} / \mathrm{FiD}^{2}$ \\
\hline Follows lessons well & "fully applies" to "does not apply" & $\begin{array}{l}\text { 4-point } \\
\text { Likert scale } \\
\text { (normalized) }\end{array}$ & $\mathrm{SOEP} / \mathrm{FiD}^{2}$ \\
\hline Gets along well with classmates & "fully applies" to "does not apply" & $\begin{array}{l}\text { 4-point } \\
\text { Likert scale } \\
\text { (normalized) }\end{array}$ & $\mathrm{SOEP} / \mathrm{FiD}^{2}$ \\
\hline
\end{tabular}

Table A.7 to be continued. 
Table A.7 continued.

\begin{tabular}{|c|c|c|c|}
\hline Variable & Description & Type & Data source \\
\hline Gets along well with teacher & "fully applies" to "does not apply" & $\begin{array}{l}\text { 4-point } \\
\text { Likert scale } \\
\text { (normalized) }\end{array}$ & $\mathrm{SOEP} / \mathrm{FiD}^{2}$ \\
\hline \multicolumn{4}{|l|}{ Combined non-cognitive skills scores } \\
\hline Non-cognitive skills (weighted) & $\begin{array}{l}\text { Summary index of all outcomes from } \\
\text { SDQ and attitude toward school (see } \\
\text { above). Based on Anderson (2008) }\end{array}$ & $\begin{array}{l}\text { Continuous } \\
\text { (normalized) }\end{array}$ & $\mathrm{SOEP} / \mathrm{FiD}^{2}$ \\
\hline Difficulties (from SDQ) & $\begin{array}{l}\text { Average of the } 4 \text { "difficulties" variables } \\
\text { from the SDQ (see below): No emotional } \\
\text { symptoms, no conduct problems, not hy- } \\
\text { peractive, no peer problems } \\
\text { (higher number = fewer problems) }\end{array}$ & $\begin{array}{l}\text { Continuous } \\
\text { (normalized) }\end{array}$ & $\mathrm{SOEP} / \mathrm{FiD}^{2}$ \\
\hline
\end{tabular}

\begin{tabular}{|c|c|c|c|}
\hline \multicolumn{4}{|c|}{ GROUP VARIABLES FOR HETEROGENEITY ANALYSIS } \\
\hline Household income $>/<$ median $^{3}$ & Median calculated within sample & Binary & $\mathrm{SOEP} / \mathrm{FiD}^{4}$ \\
\hline University/No university & At least 1 parent has university degree & Binary & $\mathrm{SOEP} / \mathrm{FiD}^{5}$ \\
\hline High/low education (parents) & $\begin{array}{l}\text { At least } 1 \text { parent has upper sec. school de- } \\
\text { gree (university entrance certificate) }\end{array}$ & Binary & $\mathrm{SOEP} / \mathrm{FiD}^{5}$ \\
\hline Migration background (child) & $\begin{array}{l}\text { Yes if direct or indirect migration back- } \\
\text { ground }\end{array}$ & Binary & $\mathrm{SOEP} / \mathrm{FiD}^{6}$ \\
\hline Gender & Male/female & Binary & $\mathrm{SOEP} / \mathrm{FiD}^{6}$ \\
\hline \multicolumn{4}{|l|}{ CONTROL VARIABLES } \\
\hline \multicolumn{4}{|l|}{ Individual characteristics } \\
\hline Female & 0 “male", 1 "female" & Binary & $\mathrm{SOEP} / \mathrm{FiD}^{6}$ \\
\hline Migration background (child) & Direct or indirect migration background & Binary & $\mathrm{SOEP} / \mathrm{FiD}^{6}$ \\
\hline Late school enrollment & Year of school enrolment $>$ Birth year +6 & Binary & $\mathrm{SOEP} / \mathrm{FiD}^{6}$ \\
\hline Year of school enrollment & $\begin{array}{l}\text { Source 1: Directly asked at age } 8 \\
\text { Source 2: Directly asked at age } 10 \\
\text { Source 3: Legal school entry year calcu- } \\
\text { lated from birth month \& cutoff date }\end{array}$ & $\begin{array}{l}\text { Categorical } \\
\text { (fixed effects) }\end{array}$ & $\mathrm{SOEP} / \mathrm{FiD}^{2,6}$ \\
\hline \multicolumn{4}{|c|}{ Parental, family and household characteristics } \\
\hline Age of mother at birth & Birth year child - birth year mother & Continuous & $\mathrm{SOEP} / \mathrm{FiD}^{6}$ \\
\hline Parent with Abitur & $\begin{array}{l}\text { At least } 1 \text { parent has upper sec. school de- } \\
\text { gree (university entrance certificate) }\end{array}$ & Binary & $\mathrm{SOEP} / \mathrm{FiD}^{5}$ \\
\hline Parent with university degree & At least 1 parent has university degree & Binary & $\mathrm{SOEP} / \mathrm{FiD}^{5}$ \\
\hline Actual work hours of parents ${ }^{3}$ & $\begin{array}{l}\text { Average of both parents, } \\
\text { rescaled such that } 40 \mathrm{~h}=1\end{array}$ & Continuous & $\mathrm{SOEP} / \mathrm{FiD}^{5}$ \\
\hline Only one parent at home ${ }^{3}$ & $\begin{array}{l}\text { Parent in household if household ID } \\
\text { (parent) })^{7}=\text { household ID (child) }\end{array}$ & Binary & $\mathrm{SOEP} / \mathrm{FiD}^{6}$ \\
\hline $\mathrm{Nb}$ of children under 16 in $\mathrm{HH}^{3}$ & Calculated from fieldwork information & Continuous & $\mathrm{SOEP} / \mathrm{FiD}^{1}$ \\
\hline
\end{tabular}

Table A.7 to be continued. 
Table A.7 continued.

\begin{tabular}{|c|c|c|c|}
\hline Variable & Description & Type & Data source \\
\hline Rural area ${ }^{3}$ & $\begin{array}{l}\text { Population in town of residence }<20,000 \\
\text { (fieldwork information) }\end{array}$ & Binary & $\mathrm{SOEP} / \mathrm{FiD}^{9}$ \\
\hline Large city ${ }^{3}$ & $\begin{array}{l}\text { Population in town of residence }>100,000 \\
\text { (fieldwork information) }\end{array}$ & Binary & $\mathrm{SOEP} / \mathrm{FiD}^{9}$ \\
\hline Log monthly net $\mathrm{HH}$ income ${ }^{3}$ & If missing: 1st imputed value & Continuous & $\mathrm{SOEP} / \mathrm{FiD}^{4}$ \\
\hline Missing: Work hours (parents) & "Actual work hours of parents" missing ${ }^{11}$ & Binary & - \\
\hline Missing: Mother's age & "Age of mother at birth" missing ${ }^{11}$ & Binary & - \\
\hline Missing: Migration background & “Migr. background (child)” missing ${ }^{11}$ & Binary & - \\
\hline \multicolumn{4}{|c|}{ County-level characteristics (merged for the county of residence ${ }^{9}$ ) } \\
\hline Share of employed (\%) & 2012 & Continuous & INKAR $^{8}$ \\
\hline Yearly GDP/person (1000 euros) & 2012 & Continuous & INKAR $^{8}$ \\
\hline Av. monthly $\mathrm{HH}$ income (euros) & 2012, per adult member of the household & Continuous & INKAR $^{8}$ \\
\hline Share highly qualified workers (\%) & 2012 & Continuous & INKAR $^{8}$ \\
\hline School age population share (\%) & 2012 & Continuous & INKAR $^{8}$ \\
\hline Pupils share (\%) & 2012 & Continuous & INKAR $^{8}$ \\
\hline Share foreign pupils (\%) & 2012 & Continuous & INKAR $^{8}$ \\
\hline Share students with Abitur (\%) & 2012 & Continuous & INKAR $^{8}$ \\
\hline Share students without degree (\%) & 2012 & Continuous & INKAR $^{8}$ \\
\hline Share children in daycare $(\%)$ & 2012 & Continuous & INKAR $^{8}$ \\
\hline Share village population (\%) & 2012 & Continuous & INKAR $^{8}$ \\
\hline Population within $100 \mathrm{~km}$ radius & In 1000, 2012 & Continuous & INKAR $^{8}$ \\
\hline Youth unemployment rate (\%) & 2012 & Continuous & INKAR $^{8}$ \\
\hline Child poverty rate $(\%)$ & 2012 & Continuous & INKAR $^{8}$ \\
\hline Net incoming commuter share (\%) & Workers, 2012 & Continuous & INKAR $^{8}$ \\
\hline County identifier ${ }^{3}$ & Used to include fixed effects & Categorical & $\mathrm{SOEP} / \mathrm{FiD}^{9}$ \\
\hline \multicolumn{4}{|l|}{ Music school characteristics ${ }^{10}$} \\
\hline Participation at JeKi & Acts as JeKi cooperating partner & Binary & Music schools \\
\hline Number of students & Taking classes at music school & Continuous & Music schools \\
\hline Total revenues (1000 Euros) & Per year & Continuous & Music schools \\
\hline Cooperations with schools & Number per year & Continuous & Music schools \\
\hline Share federal state subsidies & Share of total revenues & Continuous & Music schools \\
\hline Share basic classes & Among total classes given & Continuous & Music schools \\
\hline Share instrument lessons & Among total classes given & Continuous & Music schools \\
\hline Share ensemble lessons & Among total classes given & Continuous & Music schools \\
\hline Missing: Music school information & Any music school covariate missing ${ }^{11}$ & Binary & - \\
\hline
\end{tabular}

\footnotetext{
1 The KIDLONG file contains all child-related information, which was survey in the SOEP or FiD household questionnaire.

${ }^{2}$ Mother-child questionnaires answered by parent in the year the child turns 6,8 and 10 .

3 Time-varying covariates were measured in the first year they were available between age 7 and 11 . They were measured at age 7 ( $63 \%$ of the sample), $8(13 \%), 9(12 \%)$ or $10(12 \%)$.
} 
4 The HGEN file contains household-related information generated from answers to the household questionnaire.

5 The PGEN file contains person-related information generated from answers to current and previous individual questionnaires.

6 The PPFAD file contains person-related meta data available for SOEP and FiD.

7 The parent identifiers were taken from the KIDLONG file.

8 The INKAR file contains detailed statistics on various regional levels and is provided by the Federal Institute for Research on Building, Urban Affairs and Spatial Development (BBSR, 2015).

${ }^{9}$ Regional information on the place of residence of SOEP and FiD households is stored on a secure server on site at DIW Berlin.

10 These numbers are either for year 2008 (for children whose covariates were measured in 2010 or before) or 2012 (for children whose covariates were measured in 2011 or later).

${ }^{11}$ Missing covariates were replaced by 0 (binary variables) or their mean (continuous variables). Missing indicators were included as additional control variables. The results are robust to only examining the subsample without missing covariates.

Figure A.5 - Number of observations in treatment and control group for the two outcome group subsamples

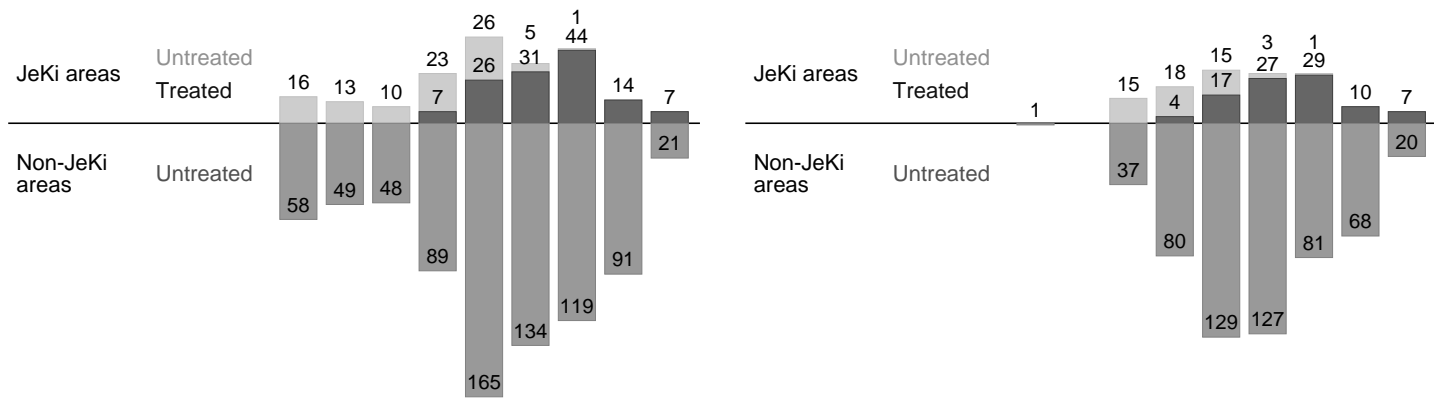

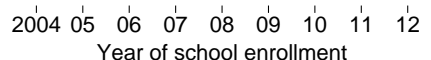

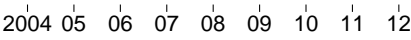
Source: SOEP v30 and FiD v4, own calculations. Year of school enrollment 
Figure A.6 - Distribution of children by treatment status and music school fee level

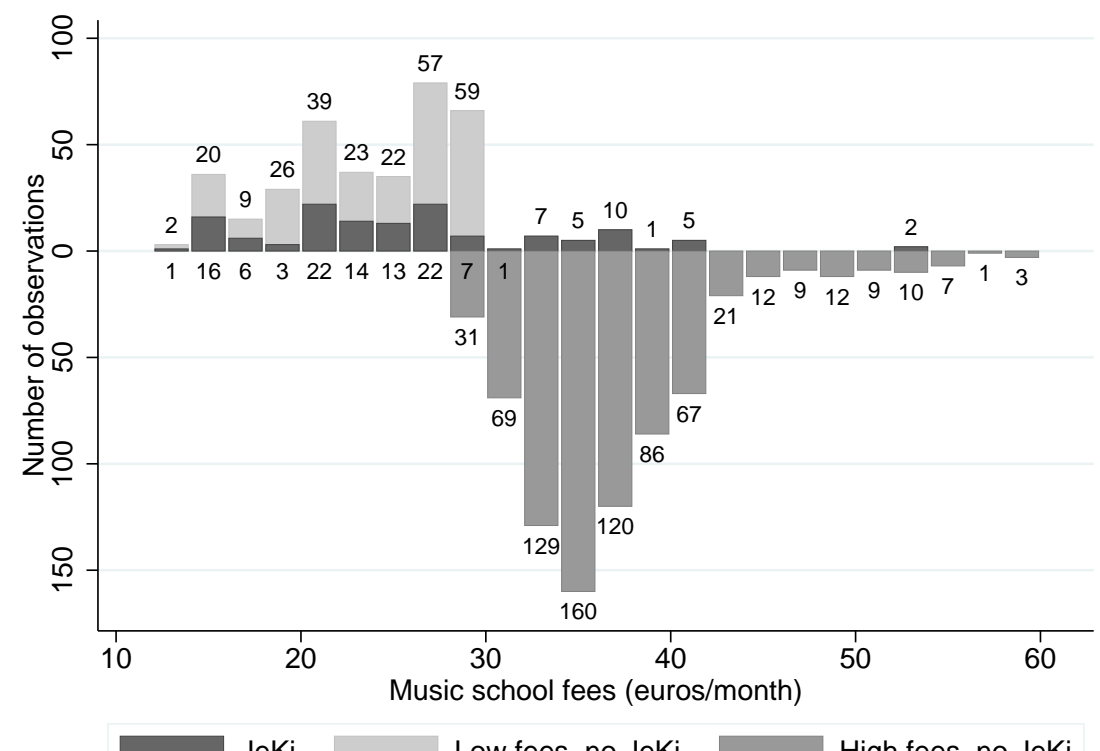

Source: SOEP v30 and FiD v4, own calculations. The figure shows the distribution of observations within 2 Euro-windows of monthly music school fees. The bars with three different shadings represent the three groups of the combined treatment. The two main treatments (JeKi share above $50 \%$ and music school fees below 33rd percentile) are visible as well. In the first, JeKi students (darkest gray) are simply compared to everyone else. In the second, I contrast areas with low and high music school fees (left and right part of the graph), irrespective of whether JeKi exists. Average music school fees in North Rhine-Westphalia vary between 12 and 60 Euros per month. The 33rd percentile is at 29.4 Euros, which explains why both bars, representing low and high fee levels, are visible in the interval ranging from 28 Euros to 30 Euros. 
Appendix A.2. Summary statistics

Table A.8 - Summary statistics of all treatment variables

\begin{tabular}{|c|c|c|c|c|c|}
\hline & Mean & $\begin{array}{l}\text { Standard } \\
\text { deviation }\end{array}$ & Minimum & Maximum & $\begin{array}{c}\text { Sample } \\
\text { size }\end{array}$ \\
\hline \multicolumn{6}{|l|}{ Main treatment definitions } \\
\hline Jeki share $>50 \%$ & 0.12 & 0.32 & 0.00 & 1.00 & 1138 \\
\hline Music sc. fees in lowest third & 0.32 & 0.46 & 0.00 & 1.00 & 1138 \\
\hline \multicolumn{6}{|l|}{ Alternative definitions of JeKi } \\
\hline Jeki share $>5 \%$ & 0.19 & 0.39 & 0.00 & 1.00 & 1138 \\
\hline Jeki share $>50 \%$ (no radius limit) & 0.12 & 0.32 & 0.00 & 1.00 & 1138 \\
\hline JeKi share (continuous) & 0.12 & 0.28 & 0.00 & 1.00 & 1138 \\
\hline JeKi share (weighted by distance) & 0.12 & 0.28 & 0.00 & 1.00 & 1138 \\
\hline JeKi at closest school & 0.11 & 0.32 & 0.00 & 1.00 & 1138 \\
\hline JeKi at 1 of 5 closest schools & 0.19 & 0.39 & 0.00 & 1.00 & 1138 \\
\hline \multicolumn{6}{|c|}{ Alternative definitions for music school fees } \\
\hline Music school fees $<$ median & 0.61 & 0.49 & 0.00 & 1.00 & 1138 \\
\hline Music school fees < average & 0.43 & 0.49 & 0.00 & 1.00 & 1138 \\
\hline Monthly fees (in euros) & 32.56 & 8.15 & 13.07 & 58.35 & 1138 \\
\hline Monthly fees (in euros, alt. def.) & 27.19 & 12.66 & 9.84 & 284.31 & 1138 \\
\hline Fees in lowest third (alt. def.) & 0.32 & 0.47 & 0.00 & 1.00 & 1138 \\
\hline \multicolumn{6}{|l|}{ Placebo treatments } \\
\hline Jeki share > 50\% (placebo) & 0.16 & 0.36 & 0.00 & 1.00 & 1138 \\
\hline Fees in lowest third (placebo) & 0.44 & 0.50 & 0.00 & 1.00 & 1138 \\
\hline
\end{tabular}


Table A.9 - Summary statistics of all outcome variables

\begin{tabular}{|c|c|c|c|c|c|}
\hline & Mean & $\begin{array}{l}\text { Standard } \\
\text { deviation }\end{array}$ & Minimum & Maximum & $\begin{array}{c}\text { Sample } \\
\text { size }\end{array}$ \\
\hline \multicolumn{6}{|l|}{ MUSiC ACTIVITIES } \\
\hline Plays music & 0.37 & 0.48 & 0.00 & 1.00 & 997 \\
\hline \multicolumn{6}{|l|}{ NON-COGNITIVE SKILLS } \\
\hline \multicolumn{6}{|c|}{ Strengths and Difficulties Questionnaire } \\
\hline No emotional symptoms & -0.04 & 1.01 & -3.51 & 0.90 & 689 \\
\hline No conduct problems & -0.02 & 0.99 & -3.29 & 0.88 & 689 \\
\hline Not hyperactive & -0.04 & 1.00 & -2.78 & 1.29 & 689 \\
\hline No peer problems & -0.01 & 1.01 & -3.85 & 0.90 & 689 \\
\hline Pro-social behavior & 0.01 & 1.00 & -3.03 & 1.08 & 689 \\
\hline \multicolumn{6}{|l|}{ Attitude towards school } \\
\hline Likes to go to school & -0.04 & 1.01 & -3.72 & 0.82 & 689 \\
\hline Likes to study & -0.03 & 1.00 & -2.83 & 1.05 & 689 \\
\hline Follows lessons well & -0.04 & 1.02 & -3.75 & 0.78 & 689 \\
\hline \multicolumn{6}{|l|}{ Gets along well... } \\
\hline ...with classmates & 0.05 & 0.97 & -1.39 & 1.05 & 689 \\
\hline ...with teacher & -0.00 & 0.99 & -2.52 & 0.60 & 689 \\
\hline \multicolumn{6}{|c|}{ Aggregated non-cognitive skills scores } \\
\hline Non-cog. skills (aggregate) & -0.02 & 0.58 & -2.15 & 0.94 & 689 \\
\hline Difficulties (from SDQ) & -0.04 & 1.00 & -3.90 & 1.40 & 689 \\
\hline
\end{tabular}

Source: SOEP v30 and FiD v4, own calculations. Outcomes in the groups "Strengths and Difficulties Questionnaire" and "Attitude toward school" were normalized with mean 0 and a standard deviation of 1 within the control group of the JeKi program treatment (i.e. children living in areas, which never had the JeKi program). 
Table A.10 - Summary statistics of all control variables

\begin{tabular}{|c|c|c|c|c|c|}
\hline & Mean & $\begin{array}{l}\text { Standard } \\
\text { deviation }\end{array}$ & Minimum & Maximum & $\begin{array}{c}\text { Sample } \\
\text { size }\end{array}$ \\
\hline \multicolumn{6}{|l|}{ Individual and family characteristics } \\
\hline Female & 0.50 & 0.50 & 0.00 & 1.00 & 1138 \\
\hline Migration background (child) & 0.35 & 0.48 & 0.00 & 1.00 & 1138 \\
\hline Late school enrollment & 0.53 & 0.50 & 0.00 & 1.00 & 1138 \\
\hline Age of mother at birth & 29.8 & 5.3 & 16.0 & 47.0 & 1138 \\
\hline Parent with Abitur & 0.34 & 0.47 & 0.00 & 1.00 & 1138 \\
\hline Parent with university degree & 0.28 & 0.45 & 0.00 & 1.00 & 1138 \\
\hline Actual work hours of parents & 0.57 & 0.32 & 0.00 & 1.75 & 1138 \\
\hline Only one parent at home & 0.15 & 0.36 & 0.00 & 1.00 & 1138 \\
\hline $\mathrm{Nb}$ of children under 16 in $\mathrm{HH}$ & 2.6 & 1.1 & 1.0 & 8.0 & 1138 \\
\hline Rural area & 0.14 & 0.35 & 0.00 & 1.00 & 1138 \\
\hline Large city & 0.40 & 0.49 & 0.00 & 1.00 & 1138 \\
\hline Log monthly net HH income & 7.9 & 0.5 & 6.0 & 10.5 & 1138 \\
\hline Missing: Work hours (parents) & 0.07 & 0.26 & 0.00 & 1.00 & 1138 \\
\hline Missing: Mother's age & 0.02 & 0.13 & 0.00 & 1.00 & 1138 \\
\hline Missing: Migration background & 0.01 & 0.10 & 0.00 & 1.00 & 1138 \\
\hline Year of school enrollment & 2008 & 2 & 2004 & 2012 & 1138 \\
\hline \multicolumn{6}{|l|}{ County-level characteristics } \\
\hline Share of employed (\%) & 52 & 3 & 44 & 57 & 1138 \\
\hline Yearly GDP/person (1000 euros) & 33 & 9 & 21 & 70 & 1138 \\
\hline Av. monthly HH income/person (euros) & 1701 & 158 & 1359 & 2177 & 1138 \\
\hline Share highly qualified workers (\%) & 6 & 3 & 3 & 18 & 1138 \\
\hline School age population share (\%) & 14 & 1 & 11 & 17 & 1138 \\
\hline Pupils share (\%) & 12 & 1 & 10 & 14 & 1138 \\
\hline Share foreign pupils $(\%)$ & 9 & 5 & 2 & 21 & 1138 \\
\hline Share students with Abitur (\%) & 36 & 5 & 25 & 52 & 1138 \\
\hline Share students without degree (\%) & 5 & 1 & 3 & 9 & 1138 \\
\hline Share children in daycare $(\%)$ & 18 & 3 & 12 & 26 & 1138 \\
\hline Share village population (\%) & 6 & 12 & 0 & 68 & 1138 \\
\hline Population within $100 \mathrm{~km}$ radius & 960 & 523 & 217 & 1916 & 1138 \\
\hline Youth unemployment rate (\%) & 19 & 2 & 15 & 23 & 1138 \\
\hline Child poverty rate $(\%)$ & 18 & 7 & 7 & 35 & 1138 \\
\hline Net incoming commuter share (\%) & -3 & 20 & -46 & 43 & 1138 \\
\hline County identifier & 5509 & 299 & 5111 & 5978 & 1138 \\
\hline \multicolumn{6}{|l|}{ Music school characteristics } \\
\hline Participation at JeKi & 0.29 & 0.45 & 0.00 & 1.00 & 1138 \\
\hline Number of students & 2169 & 2094 & 112 & 11347 & 1138 \\
\hline Total revenues (1000 Euros) & 1891 & 1798 & 41 & 7294 & 1138 \\
\hline Cooperations with schools & 16.8 & 19.0 & 0.0 & 91.0 & 1138 \\
\hline Share federal state subsidies & 0.01 & 0.01 & 0.00 & 0.10 & 1138 \\
\hline Share basic classes & 0.19 & 0.09 & 0.00 & 0.53 & 1138 \\
\hline Share instrument lessons & 0.62 & 0.13 & 0.00 & 0.94 & 1138 \\
\hline Share ensemble lessons & 0.14 & 0.08 & 0.00 & 0.94 & 1138 \\
\hline Missing: Music school information & 0.03 & 0.16 & 0.00 & 1.00 & 1138 \\
\hline
\end{tabular}

Source: SOEP v30 and FiD v4, own calculations. 
Table A.1 1 - Outcome variables by treatment status (in \%)

\begin{tabular}{|c|c|c|c|c|}
\hline & $\begin{array}{l}\text { Control } \\
\text { group }\end{array}$ & $\begin{array}{l}\text { Treatment } \\
\text { group }\end{array}$ & Difference & $\begin{array}{c}\text { p- } \\
\text { value }\end{array}$ \\
\hline \multicolumn{5}{|l|}{ MUSIC ACTIVITIES } \\
\hline Plays music & 0.36 & 0.47 & 0.11 & 1 \\
\hline \multicolumn{5}{|c|}{ Alternative treatment: Music school fees in lowest third } \\
\hline Plays music & 0.36 & 0.41 & 0.05 & 24 \\
\hline \multicolumn{5}{|c|}{ NON-COGNITIVE SKILLS } \\
\hline \multicolumn{5}{|c|}{ Strengths and Difficulties Questionnaire } \\
\hline No emotional symptoms & -0.02 & -0.18 & -0.16 & 13 \\
\hline No conduct problems & -0.04 & 0.01 & 0.05 & 56 \\
\hline Not hyperactive & -0.02 & -0.23 & -0.21 & 1 \\
\hline No peer problems & -0.02 & -0.05 & -0.03 & 82 \\
\hline Pro-social behavior & -0.01 & 0.08 & 0.09 & 42 \\
\hline \multicolumn{5}{|l|}{ Attitude towards school } \\
\hline Likes to go to school & -0.05 & -0.03 & 0.02 & 79 \\
\hline Likes to study & -0.05 & 0.00 & 0.05 & 62 \\
\hline Follows lessons well & -0.02 & -0.14 & -0.11 & 37 \\
\hline \multicolumn{5}{|l|}{ Gets along well... } \\
\hline ...with classmates & 0.02 & 0.15 & 0.13 & 18 \\
\hline ...with teacher & -0.01 & 0.11 & 0.12 & 16 \\
\hline \multicolumn{5}{|c|}{ Aggregated non-cognitive skills scores } \\
\hline Non-cog. skills (aggregate) & -0.02 & -0.04 & -0.02 & 62 \\
\hline Difficulties (from SDQ) & -0.04 & -0.17 & -0.13 & 23 \\
\hline
\end{tabular}

Source: SOEP v30 and FiD v4, own calculations. Treatment: Share of JeKi students among all students in the closest five schools is larger than $50 \%$ (except in the second row, where the treatment is: Average fees at the closest public music school are in the lowest third among all music schools within the federal state). 
Table A.12 - Individual and county-level background characteristics by treatment group status (in \%): Combined treatment

\begin{tabular}{|c|c|c|c|c|c|c|c|c|c|}
\hline & \multicolumn{3}{|c|}{ Mean for each treatment status } & \multicolumn{6}{|c|}{ Differences (t-tests) } \\
\hline & \multirow{2}{*}{$\begin{array}{c}\mathbf{T} \mathbf{1} \\
J e K i\end{array}$} & \multirow{2}{*}{$\begin{array}{c}\text { T2 } \\
\text { Low fees, } \\
\text { no JeKi }\end{array}$} & \multirow{2}{*}{$\begin{array}{c}\text { T3 } \\
\text { High fees } \\
\text { no JeKi }\end{array}$} & \multicolumn{2}{|c|}{$\mathbf{T} 2-\mathbf{T} 1$} & \multicolumn{2}{|c|}{ T3 - T1 } & \multicolumn{2}{|c|}{ T3 - T2 } \\
\hline & & & & Diff. & $\begin{array}{c}p- \\
\text { value }\end{array}$ & Diff. & $\begin{array}{c}p- \\
\text { value }\end{array}$ & Diff. & $\begin{array}{c}p- \\
\text { value }\end{array}$ \\
\hline \multicolumn{10}{|l|}{ County-level characteristics } \\
\hline $\begin{array}{l}\text { Av. monthly } \mathrm{HH} \text { income/person } \\
\text { (Euros) }\end{array}$ & 1584 & 1680 & 1729 & 95 & 1 & 145 & 0 & 50 & 13 \\
\hline Yearly GDP/person (1000 Euros) & 31.7 & 33.1 & 33.6 & 1.4 & 61 & 1.9 & 45 & 0.5 & 83 \\
\hline Share students with Abitur (\%) & 37.0 & 35.1 & 36.7 & -1.8 & 5 & -0.3 & 81 & 1.6 & 7 \\
\hline Share students without degree (\%) & 5.9 & 5.2 & 4.9 & -0.7 & 2 & -1.1 & 0 & -0.4 & 16 \\
\hline Youth unemployment rate (\%) & 18.5 & 19.1 & 19.6 & 0.6 & 26 & 1.1 & 4 & 0.5 & 13 \\
\hline Share foreign pupils (\%) & 11.6 & 9.1 & 8.1 & -2.5 & 2 & -3.4 & 0 & -1.0 & 24 \\
\hline Child poverty rate (\%) & 25.4 & 18.7 & 16.5 & -6.7 & 0 & -8.9 & 0 & -2.2 & 15 \\
\hline \multicolumn{10}{|l|}{ Individual-level characteristics } \\
\hline Monthly net HH income (Euros) & 308153.3 & 294437.7 & 320124.7 & -13715.6 & 60 & 11971.3 & 63 & 25686.9 & 12 \\
\hline Parent with Abitur & 35.6 & 27.6 & 35.3 & -7.9 & 19 & -0.3 & 96 & 7.6 & 6 \\
\hline Parent with university degree & 24.4 & 22.2 & 30.7 & -2.3 & 69 & 6.3 & 20 & 8.5 & 5 \\
\hline Migration background (child) & 31.9 & 37.0 & 35.0 & 5.1 & 38 & 3.1 & 59 & -2.0 & 65 \\
\hline Only one parent at home & 17.0 & 17.5 & 14.2 & 0.5 & 92 & -2.8 & 40 & -3.3 & 26 \\
\hline $\mathrm{Nb}$ of children under 16 in $\mathrm{HH}$ & 270.4 & 263.4 & 252.3 & -6.9 & 66 & -18.1 & 8 & -11.1 & 35 \\
\hline
\end{tabular}


Table A.13 - Outcomes by treatment group status: Combined treatment

\begin{tabular}{|c|c|c|c|c|c|c|c|c|c|}
\hline & \multicolumn{3}{|c|}{ Mean for each treatment status } & \multicolumn{6}{|c|}{ Differences (t-tests) } \\
\hline & \multirow{2}{*}{$\begin{array}{c}\mathbf{T 1} \\
J e K i\end{array}$} & \multirow{2}{*}{$\begin{array}{c}\text { T2 } \\
\text { Low fees, } \\
\text { no JeKi }\end{array}$} & \multirow{2}{*}{$\begin{array}{c}\text { T3 } \\
\text { High fees } \\
\text { no JeKi }\end{array}$} & \multicolumn{2}{|c|}{ T2 - T1 } & \multicolumn{2}{|c|}{ T3 - T1 } & \multicolumn{2}{|c|}{ T3 - T2 } \\
\hline & & & & Diff. & $\begin{array}{c}p- \\
\text { value }\end{array}$ & Diff. & $\begin{array}{c}p- \\
\text { value }\end{array}$ & Diff. & $\begin{array}{c}p- \\
\text { value }\end{array}$ \\
\hline \multicolumn{10}{|l|}{ MUSIC ACTIVITIES } \\
\hline Plays music & 0.47 & 0.37 & 0.36 & -0 & 9.34 & -0.11 & 1.15 & -0 & 84.28 \\
\hline \multicolumn{10}{|c|}{ NON-COGNITIVE SKILLS } \\
\hline \multicolumn{10}{|c|}{ Strengths and Difficulties Questionnaire } \\
\hline No emotional symptoms & -0.18 & -0.19 & 0.03 & -0 & 94.67 & 0.22 & 5.31 & 0 & 3.22 \\
\hline No conduct problems & 0.01 & -0.17 & 0.01 & -0 & 5.85 & -0.00 & 97.47 & 0 & 3.19 \\
\hline Not hyperactive & -0.23 & 0.05 & -0.05 & 0 & 0.91 & 0.18 & 3.54 & -0 & 33.80 \\
\hline No peer problems & -0.05 & -0.08 & 0.00 & -0 & 85.12 & 0.05 & 69.38 & 0 & 42.69 \\
\hline Pro-social behavior & 0.08 & -0.01 & -0.00 & -0 & 48.71 & -0.08 & 47.28 & 0 & 94.06 \\
\hline \multicolumn{10}{|l|}{ Attitude towards school } \\
\hline Likes to go to school & -0.03 & -0.06 & -0.05 & -0 & 79.86 & -0.02 & 84.20 & 0 & 91.20 \\
\hline Likes to study & 0.00 & -0.10 & -0.03 & -0 & 52.54 & -0.03 & 72.70 & 0 & 59.26 \\
\hline Follows lessons well & -0.14 & 0.03 & -0.04 & 0 & 27.19 & 0.10 & 46.15 & -0 & 51.13 \\
\hline Gets along well... & & & & & & & & & \\
\hline ...with classmates & 0.15 & 0.07 & 0.00 & -0 & 58.56 & -0.15 & 12.23 & -0 & 55.60 \\
\hline ...with teacher & 0.11 & -0.07 & 0.01 & -0 & 9.27 & -0.10 & 28.13 & 0 & 48.73 \\
\hline \multicolumn{10}{|c|}{ Aggregated non-cognitive skills scores } \\
\hline Non-cog. skills (aggregate) & -0.04 & -0.04 & -0.01 & 0 & 97.38 & 0.03 & 54.19 & 0 & 50.85 \\
\hline Difficulties (from SDQ) & -0.17 & -0.14 & -0.00 & 0 & 84.29 & 0.17 & 14.89 & 0 & 21.82 \\
\hline
\end{tabular}

Source: SOEP v30 and FiD v4, own calculations. 
Table A.14 - Covariates for each estimation sample

\begin{tabular}{|c|c|c|c|c|c|c|}
\hline & \multicolumn{2}{|c|}{ Music activities } & \multicolumn{2}{|c|}{ Non-cog. skills } & \multicolumn{2}{|c|}{ Combined sample } \\
\hline & Mean & Std. dev. & Mean & Std. dev. & Mean & Std. dev. \\
\hline \multicolumn{7}{|l|}{ Individual and family characteristics } \\
\hline Female & 0.50 & 0.50 & 0.51 & 0.50 & 0.49 & 0.50 \\
\hline Migration background (child) & 0.35 & 0.48 & 0.40 & 0.49 & 0.41 & 0.49 \\
\hline Late school enrollment & 0.55 & 0.50 & 0.34 & 0.47 & 0.32 & 0.47 \\
\hline Age of mother at birth & 29.8 & 5.3 & 29.7 & 5.4 & 29.8 & 5.4 \\
\hline Parent with Abitur & 0.33 & 0.47 & 0.34 & 0.47 & 0.33 & 0.47 \\
\hline Parent with university degree & 0.29 & 0.45 & 0.27 & 0.45 & 0.28 & 0.45 \\
\hline Actual work hours of parents & 0.57 & 0.32 & 0.58 & 0.32 & 0.58 & 0.31 \\
\hline Only one parent at home & 0.13 & 0.34 & 0.23 & 0.42 & 0.21 & 0.41 \\
\hline $\mathrm{Nb}$ of children under 16 in $\mathrm{HH}$ & 2.6 & 1.1 & 2.8 & 1.1 & 2.8 & 1.1 \\
\hline Rural area & 0.14 & 0.35 & 0.16 & 0.37 & 0.16 & 0.37 \\
\hline Large city & 0.39 & 0.49 & 0.40 & 0.49 & 0.39 & 0.49 \\
\hline Log monthly net HH income & 7.9 & 0.5 & 7.9 & 0.5 & 7.9 & 0.5 \\
\hline Missing: Work hours (parents) & 0.08 & 0.26 & 0.08 & 0.28 & 0.09 & 0.29 \\
\hline Missing: Mother's age & 0.01 & 0.11 & 0.02 & 0.13 & 0.01 & 0.10 \\
\hline Missing: Migration background & 0.01 & 0.10 & 0.01 & 0.10 & 0.01 & 0.10 \\
\hline Year of school enrollment & 2008 & 2 & 2009 & 2 & 2009 & 1 \\
\hline \multicolumn{7}{|l|}{ County-level characteristics } \\
\hline Share of employed (\%) & 52 & 3 & 52 & 3 & 52 & 3 \\
\hline Yearly GDP/person (1000 euros) & 33 & 9 & 34 & 9 & 34 & 9 \\
\hline Av. monthly HH income/person (euros) & 1702 & 159 & 1704 & 155 & 1708 & 155 \\
\hline Share highly qualified workers (\%) & 6 & 3 & 6 & 3 & 6 & 3 \\
\hline School age population share (\%) & 14 & 1 & 14 & 1 & 14 & 1 \\
\hline Pupils share $(\%)$ & 12 & 1 & 12 & 1 & 12 & 1 \\
\hline Share foreign pupils (\%) & 9 & 4 & 9 & 5 & 9 & 4 \\
\hline Share students with Abitur (\%) & 36 & 5 & 36 & 5 & 36 & 5 \\
\hline Share students without degree (\%) & 5 & 1 & 5 & 1 & 5 & 1 \\
\hline Share children in daycare $(\%)$ & 18 & 3 & 18 & 3 & 18 & 3 \\
\hline Share village population (\%) & 6 & 12 & 6 & 12 & 6 & 12 \\
\hline Population within $100 \mathrm{~km}$ radius & 962 & 521 & 951 & 535 & 952 & 535 \\
\hline Youth unemployment rate (\%) & 19 & 2 & 19 & 2 & 19 & 2 \\
\hline Child poverty rate $(\%)$ & 18 & 7 & 18 & 7 & 18 & 7 \\
\hline Net incoming commuter share (\%) & -3 & 20 & -2 & 20 & -2 & 19 \\
\hline County identifier & 5510 & 301 & 5506 & 297 & 5508 & 300 \\
\hline \multicolumn{7}{|l|}{ Music school characteristics } \\
\hline Participation at JeKi & 0.29 & 0.45 & 0.28 & 0.45 & 0.28 & 0.45 \\
\hline Number of students & 2163 & 2111 & 2352 & 2287 & 2389 & 2360 \\
\hline Total revenues (1000 Euros) & 1886 & 1810 & 2027 & 1893 & 2053 & 1937 \\
\hline Cooperations with schools & 16.8 & 19.2 & 18.4 & 20.4 & 18.7 & 21.1 \\
\hline Share federal state subsidies & 0.01 & 0.01 & 0.01 & 0.01 & 0.01 & 0.01 \\
\hline Share basic classes & 0.19 & 0.09 & 0.19 & 0.09 & 0.18 & 0.09 \\
\hline Share instrument lessons & 0.62 & 0.13 & 0.63 & 0.14 & 0.63 & 0.14 \\
\hline Share ensemble lessons & 0.14 & 0.08 & 0.13 & 0.08 & 0.13 & 0.08 \\
\hline Missing: Music school information & 0.02 & 0.15 & 0.02 & 0.15 & 0.02 & 0.13 \\
\hline Sample size & \multicolumn{2}{|c|}{997} & \multicolumn{2}{|c|}{689} & \multicolumn{2}{|c|}{548} \\
\hline
\end{tabular}




\section{Appendix B. Further results}

\section{Appendix B.1. Further information for main results}

Table B.15 - Number of observations (main results)

\begin{tabular}{|c|c|c|c|c|c|c|c|c|c|c|}
\hline & \multirow{2}{*}{\multicolumn{2}{|c|}{$\begin{array}{c}\text { Full sample } \\
\text { (1) }\end{array}$}} & \multicolumn{4}{|c|}{ by household income } & \multicolumn{4}{|c|}{ by gender } \\
\hline & & & \multicolumn{2}{|c|}{ < median } & \multicolumn{2}{|c|}{$>$ median } & \multicolumn{2}{|c|}{$\begin{array}{c}\text { Male } \\
(4)\end{array}$} & \multicolumn{2}{|c|}{$\begin{array}{c}\text { Female } \\
(5)\end{array}$} \\
\hline & $T$ & C & $T$ & $C$ & $T$ & $C$ & $T$ & $C$ & $T$ & $C$ \\
\hline \multicolumn{11}{|l|}{ MUSIC ACTIVITIES } \\
\hline Plays music & 129 & 868 & 56 & 446 & 73 & 422 & 61 & 382 & 68 & 486 \\
\hline \multicolumn{11}{|c|}{ Alternative treatment: Music school fees in lowest third } \\
\hline Plays music & 314 & 683 & 161 & 341 & 153 & 342 & 149 & 294 & 165 & 389 \\
\hline \multicolumn{11}{|c|}{ NON-COGNITIVE SKILLS } \\
\hline \multicolumn{11}{|c|}{ Strengths and Difficulties Questionnaire } \\
\hline No emotional symptoms & 94 & 595 & 40 & 301 & 54 & 294 & 39 & 288 & 55 & 307 \\
\hline No conduct problems & 94 & 595 & 40 & 301 & 54 & 294 & 39 & 288 & 55 & 307 \\
\hline Not hyperactive & 94 & 595 & 40 & 301 & 54 & 294 & 39 & 288 & 55 & 307 \\
\hline No peer problems & 94 & 595 & 40 & 301 & 54 & 294 & 39 & 288 & 55 & 307 \\
\hline Pro-social behavior & 94 & 595 & 40 & 301 & 54 & 294 & 39 & 288 & 55 & 307 \\
\hline \multicolumn{11}{|l|}{ Attitude towards school } \\
\hline Likes to go to school & 94 & 595 & 40 & 301 & 54 & 294 & 39 & 288 & 55 & 307 \\
\hline Likes to study & 94 & 595 & 40 & 301 & 54 & 294 & 39 & 288 & 55 & 307 \\
\hline Follows lessons well & 94 & 595 & 40 & 301 & 54 & 294 & 39 & 288 & 55 & 307 \\
\hline Gets along well... & & & & & & & & & & \\
\hline ...with classmates & 94 & 595 & 40 & 301 & 54 & 294 & 39 & 288 & 55 & 307 \\
\hline ...with teacher & 94 & 595 & 40 & 301 & 54 & 294 & 39 & 288 & 55 & 307 \\
\hline \multicolumn{11}{|c|}{ Combined non-cognitive skills scores } \\
\hline Non-cog. skills (aggregate) & 94 & 595 & 40 & 301 & 54 & 294 & 39 & 288 & 55 & 307 \\
\hline Difficulties (from SDQ) & 94 & 595 & 40 & 301 & 54 & 294 & 39 & 288 & 55 & 307 \\
\hline
\end{tabular}


Table B.16 - $R$ squares (main results), in \%

\begin{tabular}{|c|c|c|c|c|c|}
\hline & \multirow{2}{*}{$\begin{array}{c}\text { Full sample } \\
\text { (1) }\end{array}$} & \multicolumn{2}{|c|}{ by household income } & \multicolumn{2}{|c|}{ by gender } \\
\hline & & $<$ median & $>$ median & $\begin{array}{c}\text { Male } \\
(4)\end{array}$ & $\begin{array}{c}\text { Female } \\
\text { (5) }\end{array}$ \\
\hline \multicolumn{6}{|l|}{ MUSIC ACTIVITIES } \\
\hline Plays music & 14.4 & 13.0 & 13.0 & 9.7 & 14.5 \\
\hline \multicolumn{6}{|c|}{ Alternative treatment: Music school fees in lowest third } \\
\hline Plays music & 14.4 & 14.3 & 11.4 & 9.2 & 17.2 \\
\hline \multicolumn{6}{|c|}{ NON-COGNITIVE SKILLS } \\
\hline \multicolumn{6}{|c|}{ Strengths and Difficulties Questionnaire } \\
\hline No emotional symptoms & 2.8 & 8.9 & -0.4 & 3.0 & 0.4 \\
\hline No conduct problems & 6.6 & 9.1 & 2.2 & 17.2 & 9.3 \\
\hline Not hyperactive & 16.6 & 15.7 & 8.6 & 20.1 & 15.8 \\
\hline No peer problems & 7.0 & 2.7 & 9.7 & 5.6 & 4.7 \\
\hline Pro-social behavior & 5.8 & 8.2 & -2.2 & 15.5 & -1.1 \\
\hline \multicolumn{6}{|l|}{ Attitude towards school } \\
\hline Likes to go to school & 8.6 & 6.0 & 4.1 & 10.8 & 2.8 \\
\hline Likes to study & 6.7 & 6.0 & -2.7 & 4.8 & 7.0 \\
\hline Follows lessons well & 7.3 & 0.7 & 8.2 & 3.8 & 8.9 \\
\hline \multicolumn{6}{|l|}{ Gets along well... } \\
\hline ...with classmates & 6.9 & 3.2 & 8.9 & 7.1 & 4.4 \\
\hline ...with teacher & 7.3 & 2.1 & 10.2 & 11.2 & 1.6 \\
\hline \multicolumn{6}{|c|}{ Combined non-cognitive skills scores } \\
\hline Non-cog. skills (aggregate) & 15.2 & 16.1 & 2.1 & 19.4 & 13.6 \\
\hline Difficulties (from SDQ) & 12.9 & 16.5 & 4.5 & 21.3 & 12.9 \\
\hline
\end{tabular}

Source: SOEP v30 and FiD v4, own calculations. R-squares for main estimations presented in Table 4. 
Table B.17 - Effects of treatments (main results from Table 4, including full set of outcomes for low music school-treatment)

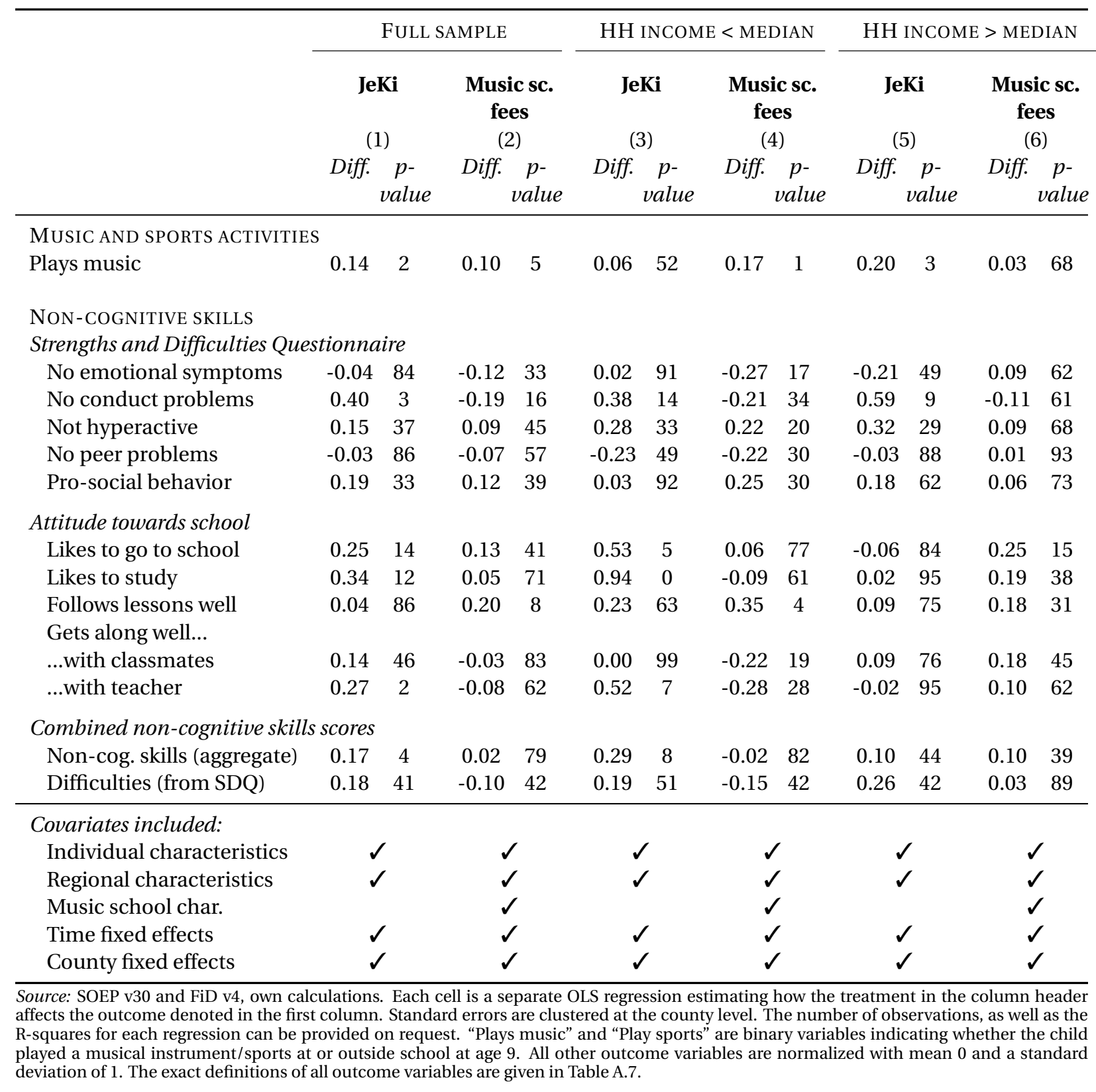


Table B.18 - Effects of treatments (OLS estimates): Heterogeneity - JeKi share above 50\%

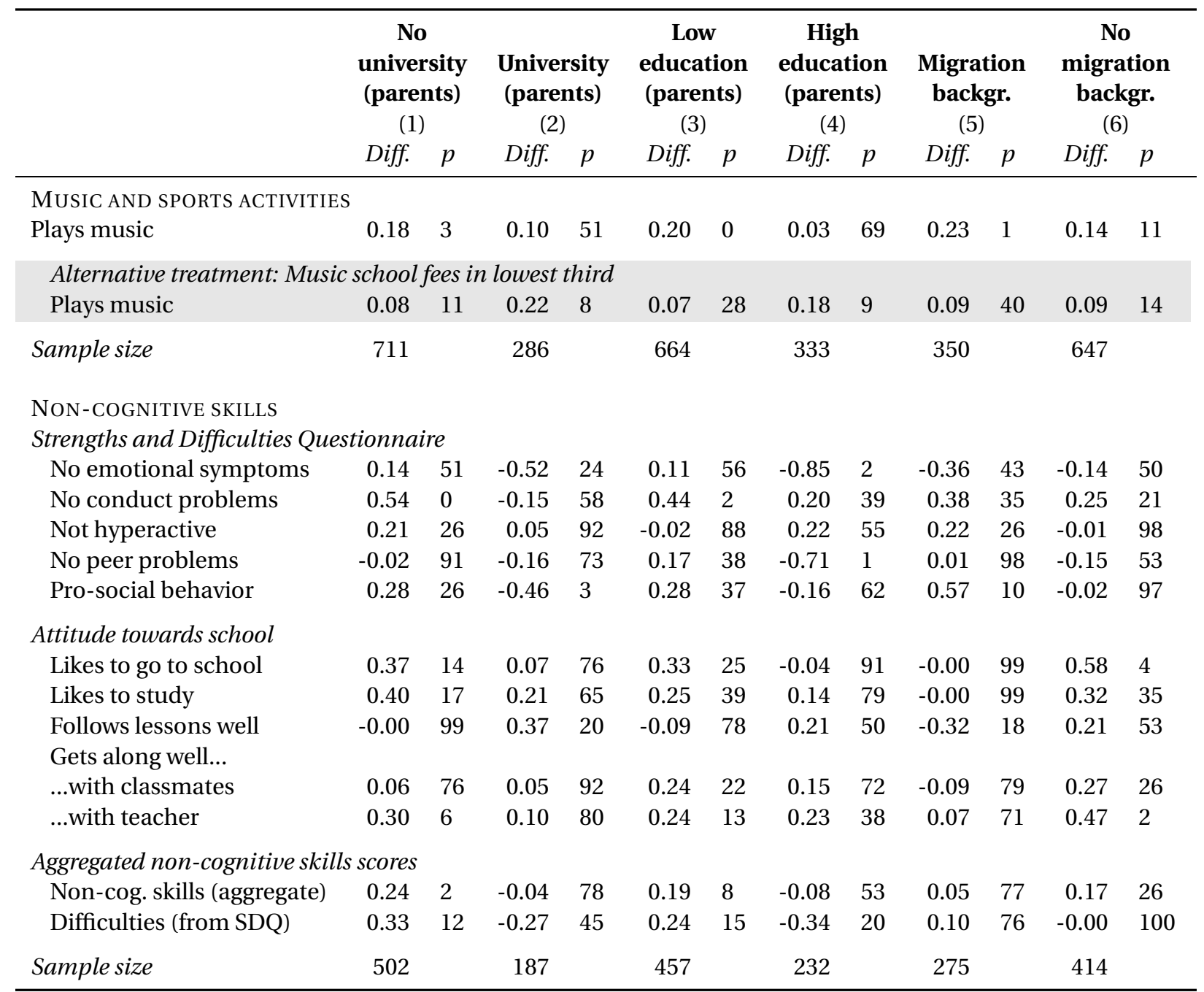

Source: SOEP v30 and FiD v4, own calculations. Each cell is a separate OLS regression estimating how access to the JeKi program affects the outcome denoted in the first column. Please refer to Section 4 for more details on the treatment definition. All regressions are estimated using difference-in-differences, and additionally control for individual and regional characteristics, as well as county fixed effects. Effects of the alternative treatment (music school fees in lowest third) are estimated with standard OLS (no difference-in-differences), additionally including music school characteristics as control variables. Standard errors are clustered at the county level. The number of observations, as well as the R-squares for each regression can be provided on request. "Plays music" is a binary variable indicating whether the child played a musical instrument at or outside school at age 9 . All other outcome variables are normalized with mean 0 and a standard deviation of 1 within the control group. The exact definitions of all outcome and control variables are given in Table A.7. 


\section{Appendix B.3. Robustness checks}

Table B.19 - Effects of treatments (OLS estimates): Variations in treatment definition - JeKi share above $50 \%$

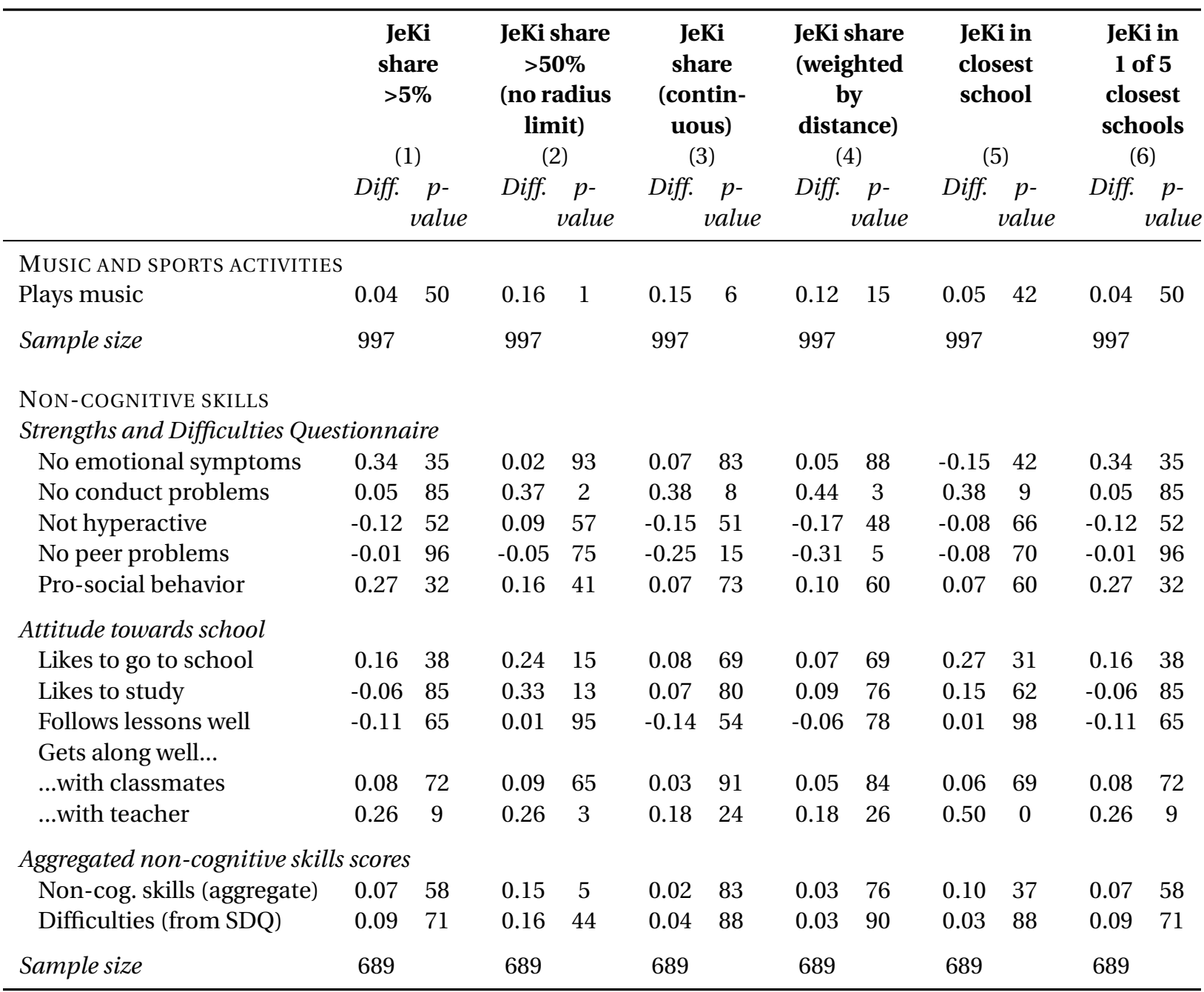

Source: SOEP v30 and FiD v4, own calculations. Each cell is a separate OLS regression estimating how access to the JeKi program (different definitions) affects the outcome denoted in the first column. Please refer to Section 4 for more details on the treatment definition. All regressions are estimated using difference-in-differences, and additionally control for individual and regional characteristics, as well as county fixed effects. Standard errors are clustered at the county level. The number of observations, as well as the R-squares for each regression can be provided on request. "Plays music" is a binary variable indicating whether the child played a musical instrument at or outside school at age 9. All other outcome variables are normalized with mean 0 and a standard deviation of 1 within the control group. The exact definitions of all outcome and control variables are given in Table A.7. 
Table B.20 - Effects of treatments (OLS estimates): Variations in treatment definition - Music school fees in lowest third

\begin{tabular}{|c|c|c|c|c|c|c|c|c|c|c|}
\hline & \multicolumn{2}{|c|}{$\begin{array}{c}\text { Fees } \\
<\text { median } \\
(1)\end{array}$} & \multicolumn{2}{|c|}{$\begin{array}{c}\text { Fees } \\
<\text { average } \\
(2)\end{array}$} & \multicolumn{2}{|c|}{ 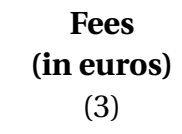 } & \multicolumn{2}{|c|}{$\begin{array}{l}\text { Fees (in euros, } \\
\text { alt. def.) } \\
(4)\end{array}$} & \multicolumn{2}{|c|}{$\begin{array}{c}\text { Fees < average } \\
\text { (alt. def.) } \\
\text { (5) }\end{array}$} \\
\hline & Diff. & $p$ & Diff. & $p$ & Diff. & $p$ & Diff. & $p$ & Diff. & $p$ \\
\hline \multicolumn{11}{|c|}{ MUSIC ACTIVITIES } \\
\hline Plays music & -0.05 & 27 & 0.03 & 63 & -0.00 & 46 & -0.00 & 38 & -0.01 & 86 \\
\hline Sample size & 997 & & 997 & & 997 & & 997 & & 997 & \\
\hline
\end{tabular}

Source: SOEP v30 and FiD v4, own calculations. Each cell is a separate OLS regression estimating how different definitions of low music school fees affect music activities. All regressions are estimated using OLS, controlling for individual, regional and music school characteristics, as well as time and county fixed effects. Standard errors are clustered at the county level. The number of observations, as well as the R-squares for each regression can be provided on request. "Plays music" is a binary variable indicating whether the child played a musical instrument at or outside school at age 9 . The exact definitions of all outcome and control variables are given in Table A.7. 
Table B.21 - Effects of treatments (OLS estimates) - Outcomes measured at age 8 or 10 only

\begin{tabular}{|c|c|c|c|c|}
\hline & \multicolumn{2}{|c|}{ Outcomes measured at age 8 only } & \multicolumn{2}{|c|}{ Outcomes measured at age 10 only } \\
\hline & Difference & $p$-value & Difference & $p$-value \\
\hline \multicolumn{5}{|l|}{ MUSIC ACTIVITIES } \\
\hline Plays music & 0.07 & 45 & 0.08 & 59 \\
\hline \multicolumn{5}{|c|}{ Alternative treatment: Music school fees in lowest third } \\
\hline Plays music & 0.05 & 32 & 0.02 & 72 \\
\hline Sample size & 769 & & 554 & \\
\hline \multicolumn{5}{|c|}{ NON-COGNITIVE SKILLS } \\
\hline \multicolumn{5}{|c|}{ Strengths and Difficulties Questionnaire } \\
\hline No emotional symptoms & 0.46 & 55 & -0.24 & 30 \\
\hline No conduct problems & 0.70 & 24 & 0.65 & 0 \\
\hline Not hyperactive & 0.46 & 19 & -0.02 & 95 \\
\hline No peer problems & -0.15 & 73 & -0.05 & 82 \\
\hline Pro-social behavior & -0.10 & 61 & 0.05 & 81 \\
\hline \multicolumn{5}{|l|}{ Attitude towards school } \\
\hline Likes to go to school & -0.22 & 52 & 0.28 & 15 \\
\hline Likes to study & 0.52 & 5 & 0.17 & 49 \\
\hline Follows lessons well & 0.30 & 39 & -0.16 & 53 \\
\hline \multicolumn{5}{|l|}{ Gets along well... } \\
\hline ...with classmates & 0.23 & 39 & 0.20 & 35 \\
\hline ...with teacher & 0.07 & 70 & 0.14 & 48 \\
\hline \multicolumn{5}{|c|}{ Aggregated non-cognitive skills scores } \\
\hline Non-cog. skills (aggregate) & 0.06 & 42 & 0.13 & 15 \\
\hline Difficulties (from SDQ) & 0.59 & 42 & 0.15 & 58 \\
\hline Sample size & 383 & & 467 & \\
\hline
\end{tabular}

Source: SOEP v30 and FiD v4, own calculations. Each cell is a separate OLS regression estimating how access to the JeKi program affects the outcome denoted in the first column. Please refer to Section 4 for more details on the treatment definition. All regressions are estimated using difference-in-differences, and additionally control for individual and regional characteristics, as well as county fixed effects. Effects of the alternative treatment (music school fees in lowest third) are estimated with standard OLS (no difference-in-differences), additionally including music school characteristics as control variables. Standard errors are clustered at the county level. The number of observations, as well as the R-squares for each regression can be provided on request. "Plays music" is a binary variable indicating whether the child played a musical instrument at or outside school at age 9 . All other outcome variables are normalized with mean 0 and a standard deviation of 1 within the control group. The exact definitions of all outcome and control variables are given in Table A.7. 
Table B.22 - Effects of treatments (OLS estimates) - Variations of "Playing music" variable and effects on missing indicators

JeKi share $>50 \%$

(1)

Difference p-value
Music school fees in lowest third

(2)

\begin{tabular}{|c|c|c|c|c|}
\hline & \multicolumn{2}{|c|}{ (1) } & \multicolumn{2}{|c|}{ (2) } \\
\hline & Difference & $p$-value & Difference & p-value \\
\hline \multicolumn{5}{|c|}{ VARIATIONS IN THE DEFINITION OF MUSIC ACTIVITIES } \\
\hline Music at school & 0.20 & 0 & 0.04 & 39 \\
\hline Music outside school & -0.04 & 38 & 0.04 & 30 \\
\hline Sample size & 997 & & 997 & \\
\hline Music at school (age 8) & 0.20 & 5 & 0.01 & 90 \\
\hline Music outside school (age 8) & -0.11 & 2 & 0.03 & 47 \\
\hline Sample size & 769 & & 769 & \\
\hline Music at school (age 10) & 0.02 & 83 & -0.06 & 40 \\
\hline Music outside school (age 10) & 0.07 & 48 & 0.00 & 95 \\
\hline Sample size & 554 & & 554 & \\
\hline \multicolumn{5}{|l|}{ EFFECTS ON MISSING COVARIATES } \\
\hline Missing: Work hours (parents) & 0.03 & 22 & 0.05 & 10 \\
\hline Missing: Mother's age & -0.02 & 9 & 0.01 & 31 \\
\hline Missing: Migration background & 0.02 & 20 & -0.01 & 30 \\
\hline Missing: Music school information & -0.05 & 7 & -0.00 & 88 \\
\hline Sample size & 1138 & & 1138 & \\
\hline
\end{tabular}


Table B.23 - Effects of treatments - Different estimation method

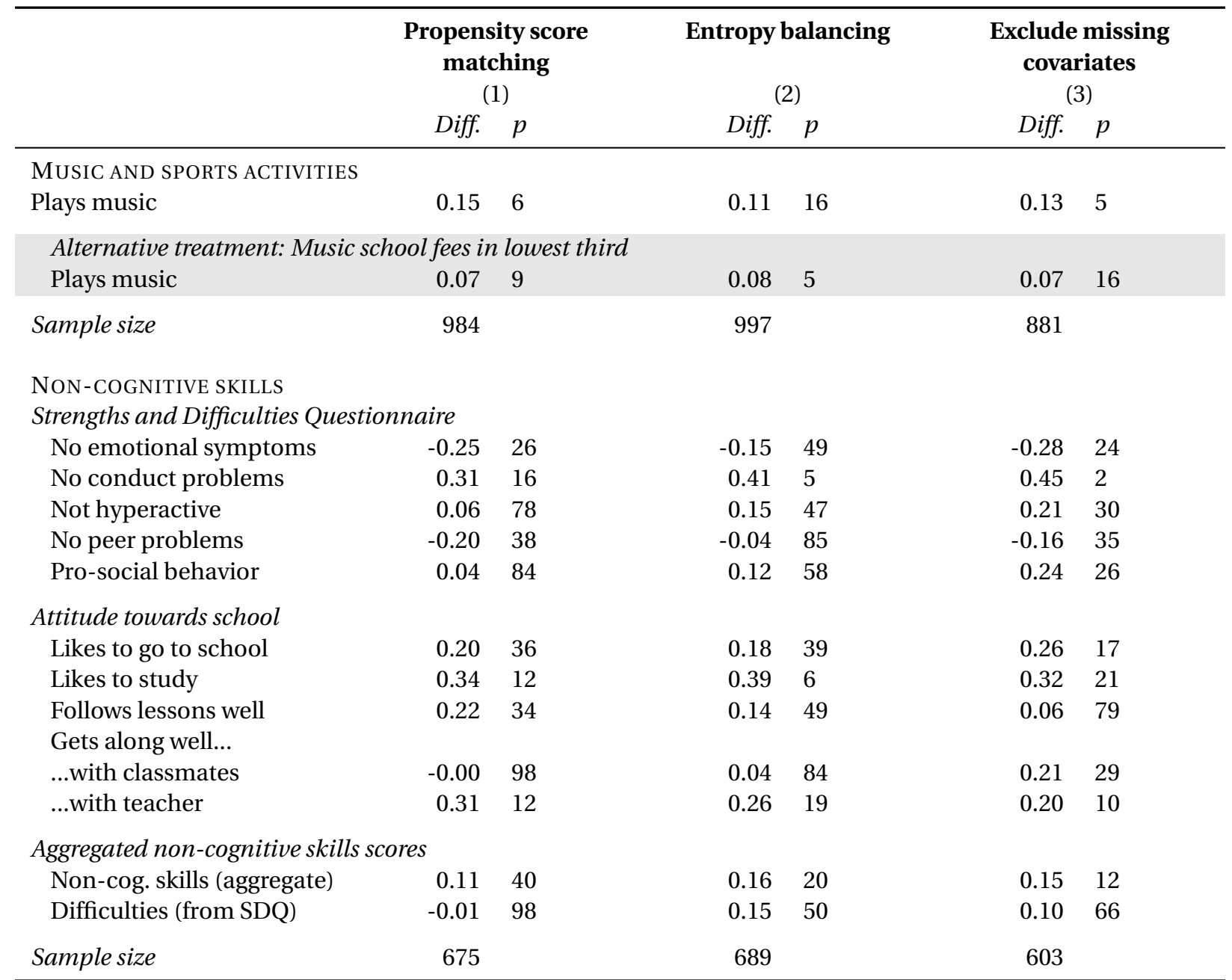

Source: SOEP v30 and FiD v4, own calculations. Each cell is a separate OLS regression estimating how access to the JeKi program affects the outcome denoted in the first column. Please refer to Section 4 for more details on the treatment definition. Regressions are estimated with different estimation methods as specified in the column headers. The first uses propensity score matching (radius matching with a caliper of $2 \%$ ), the second applies entropy balancing (Hainmueller, 2012; Hainmueller and Xu, 2013), and the third excludes all observations with at least one missing covariate. In order to ensure common support, estimations with propensity score matching only use a subset of the full list of covariates from Table A.7: gender, migration background (child), late school enrollment, parent with Abitur, parent with university degree, actual work hours of parents, only one parent at home, missing: Work hours (parents), missing: Migration background, school age population share (\%), pupils share (\%), share foreign pupils (\%), share children in daycare (\%). Standard errors are clustered at the county level. The number of observations, as well as the R-squares for each regression can be provided on request. "Plays music" is a binary variable indicating whether the child played a musical instrument at or outside school at age 9 . All other outcome variables are normalized with mean 0 and a standard deviation of 1 within the control group. The exact definitions of all outcome and control variables are given in Table A.7. 
Table B.24 - Effects of treatments (OLS estimates) - Different specifications

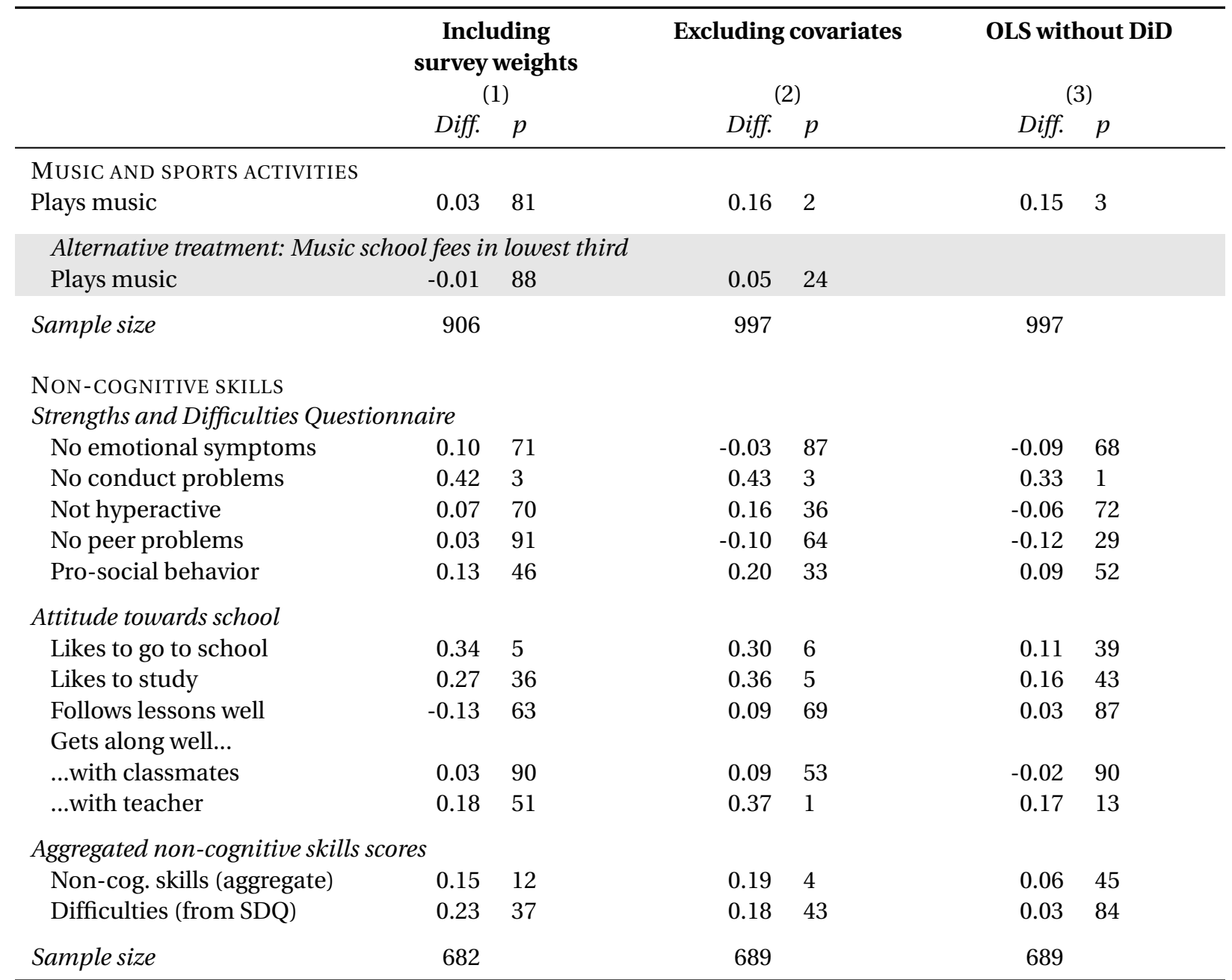

Source: SOEP v30 and FiD v4, own calculations. Each cell is a separate OLS regression estimating how access to the JeKi program affects the outcome denoted in the first column. Please refer to Section 4 for more details on the treatment definition. The first regression weights observations using survey weights, which are provided in the SOEP and FiD data to make them representative for the German population. The second regression excludes all covariates. The third regression includes all covariates, but estimates a simple OLS without the JeKi group variable that is necessary to obtain a difference-in-differences estimator. For all regressions, control variables include individual and regional characteristics, as well as time and county fixed effects. Effects of the alternative treatment (music school fees in lowest third) additionally control for music school characteristics. Standard errors are clustered at the county level. The number of observations, as well as the R-squares for each regression can be provided on request. "Plays music" is a binary variable indicating whether the child played a musical instrument at or outside school at age 9 . All other outcome variables are normalized with mean 0 and a standard deviation of 1 within the control group. The exact definitions of all outcome and control variables are given in Table A.7. 
Table B.25 - Effects of treatments (OLS estimates) - Placebo treatment and placebo outcomes

\section{Placebo treatment}

(1)
Outcomes measured

pre-treatment (age 6)

(2)

Difference $p$-value

Difference p-value

\begin{tabular}{|c|c|c|c|c|}
\hline $\begin{array}{l}\text { MusiC ACTIVITIES } \\
\text { Plays music }\end{array}$ & -0.02 & 81 & 0.01 & 94 \\
\hline $\begin{array}{l}\text { Alternative treatment: Musi } \\
\text { Plays music }\end{array}$ & \multicolumn{3}{|c|}{ Alternative treatment: Music school fees in lowest third } & 5 \\
\hline Sample size & 997 & & 343 & \\
\hline \multicolumn{5}{|c|}{ NON-COGNITIVE SKILLS } \\
\hline $\begin{array}{l}\text { No emotional symptoms } \\
\text { No conduct problems } \\
\text { Not hyperactive } \\
\text { No peer problems } \\
\text { Pro-social behavior }\end{array}$ & $\begin{array}{r}0.20 \\
-0.02 \\
0.12 \\
0.21 \\
-0.01\end{array}$ & $\begin{array}{l}56 \\
94 \\
51 \\
49 \\
99\end{array}$ & $\begin{array}{l}-0.24 \\
-0.60 \\
-0.03 \\
-0.14 \\
-0.40\end{array}$ & $\begin{array}{l}52 \\
15 \\
94 \\
75 \\
8\end{array}$ \\
\hline $\begin{array}{l}\text { Attitude towards school } \\
\text { Likes to go to school } \\
\text { Likes to study } \\
\text { Follows lessons well } \\
\text { Gets along well... } \\
\text {...with classmates } \\
\text {...with teacher }\end{array}$ & $\begin{array}{r}0.32 \\
-0.19 \\
0.06\end{array}$ & $\begin{array}{l}41 \\
55 \\
80 \\
\\
13 \\
16\end{array}$ & & \\
\hline $\begin{array}{l}\text { Aggregated non-cognitive skil } \\
\text { Non-cog. skills (aggregate) } \\
\text { Difficulties (from SDQ) }\end{array}$ & $\begin{array}{l}0.11 \\
0.17\end{array}$ & $\begin{array}{l}33 \\
40\end{array}$ & $\begin{array}{l}-0.32 \\
-0.61\end{array}$ & $\begin{array}{l}25 \\
28\end{array}$ \\
\hline Sample size & 689 & & 164 & \\
\hline
\end{tabular}

Source: SOEP v30 and FiD v4, own calculations. Each cell is a separate OLS regression estimating how access to the JeKi program affects the outcome denoted in the first column. Please refer to Table A.7 for more details on the placebo treatment variables were defined. All regressions are estimated using difference-in-differences, and additionally control for individual and regional characteristics, as well as county fixed effects. Effects of the alternative treatment (music school fees in lowest third) are estimated with standard OLS (no difference-in-differences), additionally including music school characteristics as control variables. Standard errors are clustered at the county level. The number of observations, as well as the R-squares for each regression can be provided on request. "Plays music" is a binary variable indicating whether the child played a musical instrument at or outside school at age 9 . All other outcome variables are normalized with mean 0 and a standard deviation of 1 within the control group. The exact definitions of all outcome and control variables are given in Table A.7. 
Table B.26 - Effects of treatments (OLS estimates) - Sensitivity to individual school choice

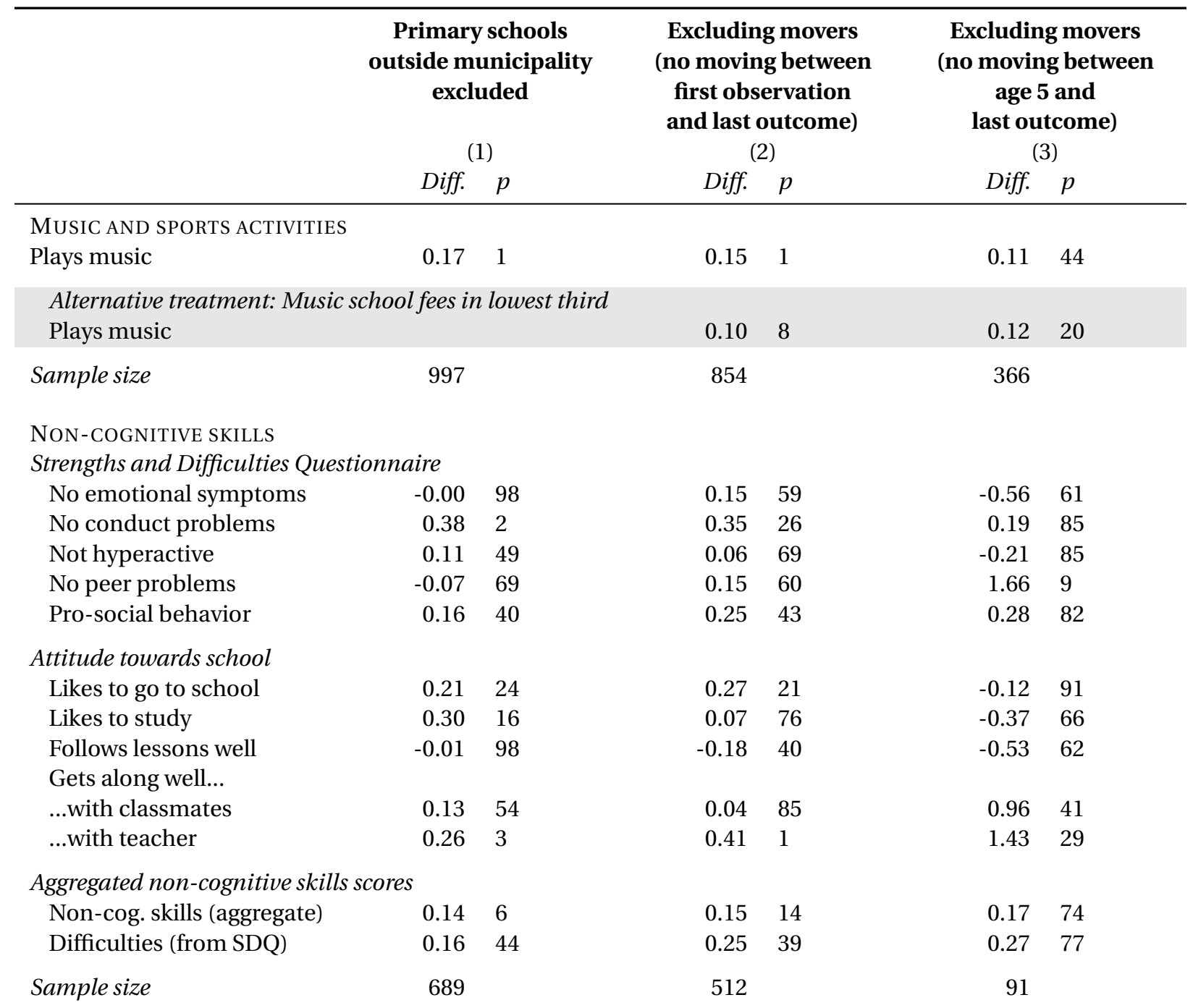

Source: SOEP v30 and FiD v4, own calculations. Each cell is a separate OLS regression estimating how access to the JeKi program affects the outcome denoted in the first column. Please refer to Section 4 for more details on the treatment definition. The first regression restricts the treatment definition to schools within the municipality (new treatment definition: JeKi share among students attending the 5 closest primary schools within municipality is larger than 50\%). The second regression excludes all individuals who moved between the first time they enter the data and the year the last outcome is observed (age 8, 9 or 10). The third regression excludes all individuals who moved at least once between age 5 and 10 . Here, the sample size is very small, given that only few children are actually observed in the data for such a long period. For most individuals, this is due to the fact that, so far, only 4 years of FiD data are available, by construction, children can thus not have been observed from age 5 to 10 . For all regressions, control variables include individual and regional characteristics, as well as time and county fixed effects. Effects of the alternative treatment (music school fees in lowest third) additionally control for music school characteristics. Standard errors are clustered at the county level. The number of observations, as well as the R-squares for each regression can be provided on request. "Plays music" is a binary variable indicating whether the child played a musical instrument at or outside school at age 9. All other outcome variables are normalized with mean 0 and a standard deviation of 1 within the control group. The exact definitions of all outcome and control variables are given in Table A.7. 